\title{
Emerging Anti-Aging Strategies - Scientific Basis and Efficacy
}

\author{
Ashok K. Shetty ${ }^{1,2, *}$, Maheedhar Kodali ${ }^{1,2}$, Raghavendra Upadhya ${ }^{1,2}$, Leelavathi N. Madhu ${ }^{1}$ \\ ${ }^{1}$ Institute for Regenerative Medicine, Department of Molecular and Cellular Medicine, Texas A\&M University \\ Health Science Center College of Medicine, College Station, Texas 77843, USA \\ ${ }^{2}$ Olin E. Teague Veterans' Medical Center, Central Texas Veterans Health Care System, Temple, Texas 76504, \\ USA
}

[Received October 17, 2018; Revised November 28, 2018; Accepted November 30, 2018]

\begin{abstract}
The prevalence of age-related diseases is in an upward trend due to increased life expectancy in humans. Age-related conditions are among the leading causes of morbidity and death worldwide currently. Therefore, there is an urgent need to find apt interventions that slow down aging and reduce or postpone the incidence of debilitating age-related diseases. This review discusses the efficacy of emerging anti-aging approaches for maintaining better health in old age. There are many anti-aging strategies in development, which include procedures such as augmentation of autophagy, elimination of senescent cells, transfusion of plasma from young blood, intermittent fasting, enhancement of adult neurogenesis, physical exercise, antioxidant intake, and stem cell therapy. Multiple pre-clinical studies suggest that administration of autophagy enhancers, senolytic drugs, plasma from young blood, drugs that enhance neurogenesis and BDNF are promising approaches to sustain normal health during aging and also to postpone age-related neurodegenerative diseases such as Alzheimer's disease. Stem cell therapy has also shown promise for improving regeneration and function of the aged or Alzheimer's disease brain. Several of these approaches are awaiting critical appraisal in clinical trials to determine their long-term efficacy and possible adverse effects. On the other hand, procedures such as intermittent fasting, physical exercise, intake of antioxidants such as resveratrol and curcumin have shown considerable promise for improving function in aging, some of which are ready for large-scale clinical trials, as they are non-invasive, and seem to have minimal side effects. In summary, several approaches are at the forefront of becoming mainstream therapies for combating aging and postponing age-related diseases in the coming years.
\end{abstract}

Key words: Aging, antioxidants, astragalus, autophagy, curcumin, intermittent fasting, neurogenesis, plasma transfusion, physical exercise, resveratrol, senescent cells, senolytics, stem cells, stem cell therapy, telomeres

The life expectancy of humans has almost doubled in developed countries in the past century. However, life extension experienced by populations resulted in an enhanced prevalence of age-related diseases [1]. Agerelated ailments such as cardiovascular disease, cancer, and neurodegenerative diseases are the leading causes of morbidity and death worldwide [2-8]. A gradual process of aging in cells, tissues, and organs accompanied by the steady waning of function are normal incidents in the lifespan of an organism. When age-related changes occur gradually, individuals achieve what is known as "successful aging," which is a condition where older individuals in sixties, seventies, and eighties show no significant disease or disability, sustain very good or reasonable cognitive function and actively participate with the life. Extending the lifespan of organisms is one

*Correspondence should be addressed to: Dr. Ashok K. Shetty, Department of Molecular and Cellular Medicine, Texas A\&M University Health Science Center College of Medicine, College Station, TX 77845, USA. E-mail: shetty@ medicine.tamhsc.edu

Copyright: () 2018 Shetty AK et al. This is an open-access article distributed under the terms of the Creative Commons Attribution License, which permits unrestricted use, distribution, and reproduction in any medium, provided the original author and source are credited. 
of the primary goals of the aging research. However, recently, a greater emphasis has been placed on maintaining a better physical and mental health during aging because a considerable percentage of older individuals are developing a variety of age-related diseases, which is not only affecting the quality of their life but also the family members who care for them [9].

Finding ways to prevent age-related diseases is all the more important because the aging population is snowballing in the world as a result of better nutrition, effective antibiotics against infectious diseases and improved healthcare. For example, in the United States, the number of people over 65 years of age is projected to reach 98 million by 2060 from the current 46 million, which would make the percentage of people over 65 years of age to $\sim 25 \%$ among the total population. Therefore, development of interventions that slow down the rate of aging and reduce or postpone the incidence of debilitating age-related diseases would be of immense value to improve the quality of life as well as to reduce medical costs [10, 11]. Studies in animal models have demonstrated that a variety of genetic, dietary and pharmacological interventions enhance lifespan [12-14]. Some of the anti-aging strategies that extend lifespan may also be useful for delaying the onset of age-related diseases. This review confers the efficacy of emerging anti-aging approaches for maintaining better health in old age. Approaches that have lately received significant interest will be discussed. These include strategies such as enhancement of autophagy, elimination of senescent cells using senolytics, transfusion of young blood, intermittent fasting, adult neurogenesis boost, physical exercise, antioxidant and herbal intake, and stem cell therapy.

Table 1. Autophagy Enhancers

\begin{tabular}{|c|c|c|}
\hline Drug & Mode of action & References \\
\hline Rapamycin & Inhibits mTORC1 activity & [202-204] \\
\hline $\begin{array}{l}\text { MSL (4-(4-fluorophenyl) sulfonyl-5- } \\
\text { methylthio-2-phenyloxazole) }\end{array}$ & Increases LC3-I to LC3-II conversion without mTOR inhibition & {$[205,206]$} \\
\hline Metformin & $\begin{array}{l}\text { Inhibits mTOR signaling and protein synthesis, activates adenosine } \\
\text { monophosphate-activated protein kinase (AMPK) }\end{array}$ & $\begin{array}{l}{[202,207,} \\
208]\end{array}$ \\
\hline Resveratrol & $\begin{array}{l}\text { Inhibits mTOR through ATP competition, promotes LC3II and } \\
\text { beclin-1 expression }\end{array}$ & $\begin{array}{l}{[202,209,} \\
210]\end{array}$ \\
\hline Perifosine & Inhibits Akt and mTOR axis components & [211] \\
\hline $\begin{array}{l}\text { RSVA314 and RSVA405 (Structural } \\
\text { similarities of Resveratrol) }\end{array}$ & $\begin{array}{l}\text { Activates AMPK to inhibit mTOR and promote autophagy to increase } \\
A \beta \text { degradation }\end{array}$ & [212] \\
\hline PREP inhibitor (KYP-2047) & Targets beclin-1 and increases LC3BII and clears $\alpha$-synuclein & {$[19,213]$} \\
\hline BRD5631 & $\begin{array}{l}\text { Autophagy through mTOR-independent pathway, NPC1, IL-1 } \beta \\
\text { Suppression }\end{array}$ & [214] \\
\hline PP242 & ATP-competitive mTOR (mTORC1 and mTORC2) inhibition & {$[215,216]$} \\
\hline Torin 1 & ATP-competitive mTOR (mTORC1 and mTORC2) inhibition & {$[217,218]$} \\
\hline PI103 & $\begin{array}{l}\text { Dual ATP-competitive mTOR (mTORC1 and mTORC2) and } \\
\text { selective PI3KC1a inhibitor }\end{array}$ & [219] \\
\hline Xestospongin B & $\begin{array}{l}\text { Inhibits IP3-mediated } \mathrm{Ca}^{2+} \text { signaling, Inhibits Beclin-1 interaction } \\
\text { with IP3R-Bcl-2 complex }\end{array}$ & {$[220,221]$} \\
\hline Everolimus & Inhibits mTOR & {$[222,223]$} \\
\hline Spermidine & $\begin{array}{l}\text { Inhibits caspase } 3 \text {-mediated Beclin } 1 \text { cleavage, Inhibits } \\
\text { acetyltransferase EP } 300\end{array}$ & {$[224,225]$} \\
\hline Rottlerin & Increased LC3-II & {$[226,227]$} \\
\hline Niclosamide & Inhibits mTORC1 pathway & {$[228,229]$} \\
\hline Pifithrin- $\alpha$ & p53 inhibitor & [230] \\
\hline Valproic acid & Suppresses Akt/mTOR pathway, Inhibits Oxidative stress & {$[231,232]$} \\
\hline IR-58 & $\begin{array}{l}\text { Inhibits mitochondrial membrane } 44 \text { (TIM44)-superoxide dismutase } 2 \\
\text { (SOD2) pathway }\end{array}$ & [233] \\
\hline Prazosin & Increases p-p53 and p-AMPK and decreases Akt/mTOR & [234] \\
\hline Verapamil & Blocks calcium channels & {$[235,236]$} \\
\hline
\end{tabular}




\section{Autophagy enhancement for facilitating successful aging}

Autophagy is a lysosomal disintegration process, which is protective housekeeping machinery to get rid of damaged cell organelles, longstanding misfolded proteins and colonizing pathogens $[15,16]$. Autophagy shields cells against stress through an activity that catabolizes intracellular elements to preserve energy homeostasis [17]. Autophagy plays a significant role in development and disease. Particularly, enhancement of autophagy has been suggested to be useful for treating a variety of conditions, including metabolic disorders, neurodegenerative diseases, cancers and infectious diseases [15]. Dysfunctional autophagy also contributes to neurodegeneration [18]. An intact autophagy function in neurons has a neuroprotective effect because autophagy facilitates the elimination of pathogenic forms of proteins such as $\alpha$-synuclein involved in Parkinson's disease [19] or tau in Alzheimer disease [20, 21]. In animal prototypes of Parkinson's disease, treatment with autophagy enhancers such as rapamycin and lithium engendered various favorable effects, which include diminished aggregation of $\alpha$-synuclein, oxidative stress, mitochondrial dysfunction, and neurodegeneration [19].

Autophagy has a significant role in the modulation of the aging process. The function of autophagy in aging is apparent from numerous studies using yeasts, worms, flies, and mice that elevated expression of autophagyrelated genes is a prerequisite for lifespan extension [17, 22]. Some studies have also shown that tissue-specific expression of single autophagy gene is adequate for extending lifespan [23] whereas other studies have pointed out that distinct types of autophagy are critical for longevity as they specifically target dysfunctional cellular components and prevent their aberrant accumulation [24]. Interestingly, slow-down of aging and longevity increase achieved through food deprivation and calorie restriction (CR) are facilitated through upregulation of autophagy because dampening autophagy diminishes the anti-aging outcomes of CR [15, 25, 26]. Besides, other studies have shown that enhancing autophagy could reinstate the regenerative capacity of aging stem cells $[27,28]$. Table 1 shows a list of autophagy enhancers tested in animal models and/or cell culture systems.

Thus, autophagy enhancing interventions that commence in middle age would likely facilitate successful aging and increased longevity. However, it is debatable whether the enhancement of autophagy alone is sufficient to combat aging. Besides, the selectivity of autophagy enhancers is essential as some proteins involved in the upstream autophagy-lysosomal pathway are also implicated in signaling pathways other than autophagy. Consequently, a wide-ranging stimulation of autophagy may result in dose-dependent side-effects, which makes them unsuitable for clinical translation [19]. TFrom this persecgive, targeting specific types and phases of the autophagic process is likely to have beneficial and disease-modifying effects in aging and neurodegenerative disorders. For example, agents that selectively affect core autophagy-lysosomal pathway components, including transcription factor EB, lysosomes, $\beta$-glucocerebrosidase (GCase) as well as chaperone-mediated autophagy regulators, have resulted in more precise effects on molecular pathologic processes causing Parkinson's disease [19]. In this context, fasting and CR appear to be most beneficial and safer alternatives as they can stimulate autophagy without adverse side effects. Some dietary supplements also stimulate autophagy with other beneficial effects on the cardiovascular and nervous systems, which include resveratrol [29-32], curcumin [27], and spermidine [33-36].

\section{Senescent cell elimination as an anti-aging therapy}

Amongst the perpetrators of organismal aging, the function of senescent cells (SCs) has caught significant interest. Cellular senescence is typified by an irreversible cell-cycle arrest, a resistance to apoptosis, and acquisition of a pro-inflammatory, tissue-destructive senescenceassociated secretory phenotype, which can be engendered via different intracellular and extracellular influences [3739]. For instance, a microbial infection can also stimulate cellular senescence [40]. Because of their incapability to proliferate, senescent cells cannot participate in standard tissue preservation and tissue repair. Rather, senescent cells disrupt the milieu by producing a plethora of bioactive factors that cause inflammation and impede regeneration [41]. Senescent cells exhibiting the cell cycle inhibitory protein p16INK4A actively propel spontaneously ensuing age-related tissue deterioration and thereby promote several diseases associated with aging [42]. Indeed, patients with neurodegenerative diseases display various markers of senescence [38, 42]. The senescence-linked secretory phenotype can also promote metabolic dysregulation, stem cell dysfunction, and loss of resilience [38]. Thus, it may be possible to defer, avert, or ameliorate multiple senescence-associated conditions just by delaying the accumulation of senescent cells or lessening the burden of senescent cells.

In several tissues and organs, senescence is a common feature during the aging process with an age-related increase in the number of senescent cells. The secretory phenotype of senescent cells fuels the chronic, proinflammatory systemic state known as inflammaging. Inflammaging is one of the conspicuous features of aging weakening the regenerative competence of stem cells and escalating the chance for developing age-related diseases 
[1]. Furthermore, a study by Musi and colleagues has shown that tau protein aggregation is accompanied by cellular senescence in the brain [43]. Additional characterization validated that senolytic drug treatment to tau transgenic mice with late-stage pathology resulted in reduced neurofibrillary tangle density, neuron loss, and ventricular enlargement. These results suggest a link between the presence of neurofibrillary tangles and cellular senescence in the brain. Another study suggested a causal connection between the accrual of senescent cells and cognition-associated neurodegeneration [37]. This study employed MAPTP301SPS19 mouse model of taudependent neurodegenerative disease that accumulates p16INK4A-positive senescent astrocytes and microglia. Clearance of senescent astrocytes and microglia using genetic approaches in these mice prevented gliosis, hyperphosphorylation of both soluble and insoluble tau, and degeneration of neurons in the cerebral cortex and the hippocampus [37]. Remarkably, these changes mediated by the clearance of senescent cells resulted in the rescue of cognitive function. Moreover, intervention with a senolytic drug also modulated tau aggregation [37]. Overall, this study suggested that elimination of senescent cells through administration of senolytic drugs is an efficient therapeutic avenue for treating neurodegenerative disorders.

Table 2. Senolytic Drugs.

\begin{tabular}{lll}
\hline Drug & Mode of action & References \\
\hline Navitoclax & Targeting Bcl-2 family & {$[237]$} \\
Fisetin & Targeting Bcl-2 family, regulation of PI3K/AKT/NF- $\kappa \beta$ to promote & {$[238-240]$} \\
& caspase-3 and inactivates ERK1/2 & \\
Quercetin & Targeting PI3K, Induction of HIF-1 $\alpha$ & {$[241,242]$} \\
Piperlongumine & Inhibits Akt/mTOR signaling, depletion of the androgen receptor & {$[243-245]$} \\
Panobinostat & Decreases Bcl-xL expression and increases acetylation of Histone 3 & {$[246]$} \\
Geldanamycin & Inhibits HSP90 & {$[247]$} \\
Dasatinib & Interacts with P53 and inhibits PAI-2 & {$[241]$} \\
A1331852 & Inhibits Bcl-xL & {$[239]$} \\
A1155463 & Inhibits Bcl-xL & {$[239]$} \\
\hline
\end{tabular}

\section{Transfusion of plasma from young individuals to promote successful aging}

A new procedure for limiting or reversing aspects of aging in various organs throughout the body is the transfusion of blood from the young to the aged, as molecules circulating in the young blood can rejuvenate the aging cells and tissues [47-49]. Since prehistoric periods, it has been believed that transfusion or consuming young blood or elements of young blood may rejuvenate the aging tissues and individuals [50]. A procedure called parabiosis, studied in animal models, has revived the
From the above, it appears that, the elimination of senescent cells using drugs referred to as senolytics would slow down aging and maintain better function during old age. In mice, senotherapy proved to be effective in models of accelerated aging and also during normal chronological aging. Senotherapy prolonged lifespan, rejuvenated the function of bone marrow, muscle and skin progenitor cells, improved vasomotor function and slowed down atherosclerosis progression [41, 44-46]. Anti-senescence activity has been identified in a variety of molecules, including synthetic senolytic drugs and natural compounds in certain types of food. An array of senolytics have recently received widespread interest. Several senolytic agents have been shown to alleviate multiple senescence-related phenotypes in pre-clinical models [45]. Table 2 shows a list of senolytics that have been shown to reduce senescent cells in animal models. However, their safety and reliability as anti-senescence drugs are yet to be ascertained in human clinical trials [1]. Because senescent cells spread inflammation at the systemic level through pro-oxidant and pro-inflammatory signals, foods rich in polyphenols, which exert antioxidant and antiinflammatory effects, have the promise to be utilized as "anti-senescence foods" in a nutraceutical approach to healthier aging [1]. perception of young blood as an efficient drug for slowing down aging and treating age-related diseases. Parabiosis meaning living beside is a procedure that anatomically joins two animals so that they share each other's circulating blood. Many studies have suggested that heterochronic parabiosis, which is joining an aged animal to a young animal, leads to a multitude of beneficial antiaging effects [51-53]. Factors in the young blood activated molecular signaling pathways in stem cells located in the liver, muscle, and brain of the old parabiont, which lead to enhanced tissue regeneration [50]. For example, transfusion of blood from a young animal to an aged 
animal enhanced adult neurogenesis as well as synaptic plasticity in the aged brain [54]. Additional studies suggested that several soluble factors underlie the rejuvenating effects of the young blood. The growth differentiation factor 11 (GDF11) is one of the wellcharacterized factors in the young blood [50]. Studies using aged mice have shown that GDF11 treatment alone can reverse age-related muscle dysfunction [55] and cardiac hypertrophy $[56,57]$, and enhance hippocampal neurogenesis, vasculature and markers of neuronal plasticity in the hippocampus and cerebral cortex.

Another study analyzed the effects of heterochronic parabiosis of Alzheimer's disease (AD) transgenic mice with young healthy mice [58]. Circulation of blood from young mice into $\mathrm{AD}$ mice did not reduce the deposition of beta-amyloid or microglial activation. However, the procedure reversed the loss of synapses and the abnormal expression of many genes involved in critical neuronal signaling pathways in the hippocampus. Furthermore, improvements in spatial working memory and associative memory were observed with repeated intravenous administration of plasma from young healthy mice to $\mathrm{AD}$ mice. These results provided the idea that young plasma has the potential for slowing down the progression of the $\mathrm{AD}$, and clinical trials testing the effect of young plasma in patients with the AD are already underway $[59,60]$. A human pilot study found that young donor plasma infusion protocols for adults with the AD are safe and feasible though statistically significant improvements in cognition are yet to be detected.

To validate the benefits of infusion of plasma collected from younger individuals for treating aged individuals or individuals with $\mathrm{AD}$, careful, placebocontrolled larger clinical trials will be required. Several issues need to be validated before recommending transfusion of plasma from younger individuals as an approach to combat aging or prevent AD. These include the age-range of younger donors having plasma that mediates beneficial effects upon transfusions into older individuals, an "optimal age" at which transfusion of plasma from younger individuals into elderly individuals would yield significant cognitive enhancement, and the volume or frequency of transfusions required to achieve substantial cognitive improvement without adverse sideeffects [54]. Also, the possible side effects need to be considered, which may include acute lung injury, circulatory overload, and allergic reactions, transmission of infections, febrile nonhemolytic transfusion reactions, red blood cell alloimmunization, and hemolytic transfusion reactions [59]. There are also ethical challenges to resolve regarding the application of young blood transfusion [61].

\section{Intermittent fasting as a means to combat aging}

Diet and eating schemes have a significant influence on the pathogenesis of many age-associated diseases, which can be gleaned from both epidemiological and experimental studies [62-66]. For example, one of the most efficient nongenetic dietary interventions that can enhance longevity is $\mathrm{CR}$, involving reduced calorie intake by about $20-40 \%$ below ad libitum $[67,68]$. A study on the dietary intake of adults living in Okinawa, a Japanese island having nearly five times higher number of centenarians than any other part of the world, revealed that Okinawan's consumed $17 \%$ fewer calories than the average adult in Japan and $40 \%$ less than the average adult in the United States [69, 70]. Many investigations in animal prototypes have demonstrated that reduced food intake leads to increased lifespan [71]. The other beneficial effects include improved gut microbiota composition and metabolome [72], reduced age-related methylation changes in the brain [73], increased adult neurogenesis $[74,75]$, improved cognitive function [7678], protection against age-related neurodegenerative disorders such as dementia [65, 79].

Recently, many studies have shown that intermittent fasting (IF) can have similar effects as CR [62, 64, 80, 81]. Benefits related to cardiovascular health include protection of heart against ischemic injury [82], reduced body mass index and blood lipids [83] improved glucose tolerance [84], and lower incidence of coronary artery disease [85]. The positive effects of IF on brain health in pre-clinical studies comprised improved cognitive function with reduced oxidative stress during middle age when IF was commenced in young adult age [86] and delayed occurrence of age-related brain impairments [87]. Moreover, in models of ischemic stroke, IF modulated forebrain neurogenesis, autophagy, and apoptosis, attenuated inflammasome activity, suppressed detrimental genetic pathways, and improved recovery [88-90]. IF was also found to be efficient for reducing neuroinflammation and preserving cognitive function after lipopolysaccharide administration, an animal model of systemic bacterial infection [91, 92]. Furthermore, IF ameliorated behavioral deficits in 3xTgAD mice [93]. In the APP/PS1 model of AD mice, IF increased $\beta$ hydroxybutyrate, which in turn, inhibited the increase of brain-derived lipoprotein lipase through down-regulation of microRNA-29a [94].

A recent study showed that IF improves tissue function and the overall health during aging in fruit flies [95]. This study demonstrated that just one month of a 2day fed:5-day fasted IF regime at the beginning of adulthood is adequate to extend lifespan. Additional analysis revealed that IF enhanced resistance to starvation, oxidative and xenobiotic stress with a higher 
lipid content, which is one of the mechanisms underlying increased longevity. Furthermore, guts of flies that underwent IF displayed a significant reduction in agerelated pathologies and improved gut barrier function with reduced relative bacterial abundance. Also, IF promoted beneficial effects without involving the target of rapamycin (TOR) pathway. Another study showed that 24-hour fasting enhanced intestinal stem cell function in young and aged mice by inducing a fatty acid oxidation program [96], which was evident from findings that acute genetic disruption of Cpt1a, the rate-limiting enzyme in fatty acid oxidation, abrogated the positive effect of fasting on stem cells.

How do the various beneficial effects of IF seen in animal studies relate to humans? Many variations of IF exist, the most common plans are defined here. A protocol involving fasting every day for 14-16 hours by restricting daily eating window to $8-10$ hours is called the $16 / 8$ method. A diet comprising a cycle of standard eating for five consecutive days followed by a restricted calorie intake (500-600 calories/day) in the next two days is named 5:2 plan. Another eating protocol involving a 24hour fast, once or twice per week is termed as eat-stop diet. The other schemes of the diet include alternate day fasting and the warrior diet. The warrior diet involves starvation during the day and eating a huge meal (feasting) at night. However, it is currently unclear which one among these diverse types of IF promotes maximal benefits or any adverse side-effects on health in the longterm, though $16 / 8$ seems to be the most popular, as it is a natural regimen to adapt.

In human studies, protocols and interpretations of IFmediated weight loss trend varied considerably [81]. Most human IF studies did not result in significant weight loss or considerable improvements in metabolic biomarkers. Quite a few questions remain to be dealt with regarding the benefits of IF on human health. First, it is unknown whether or not IF is beneficial to commence at all ages or effective in only certain age groups. Second, the benefits of IF for improving cognitive function need to be assessed in both healthy and obese males and females of different ages with various regimens and durations of IF. For example, a short-term (28 days) IF regimen did not show significant effects on body composition, glucose metabolism or cognitive function in healthy lean men [97]. Third, examining the adverse effects of IF, if any, particularly in individuals with pre-existing health conditions will be important. Fourth, the type of dietary composition which provides maximal benefits with IF needs to be identified. Finally, it will be helpful to examine the potential positive or negative interactions between IF and physical exercise.

\section{Promise of neurogenesis enhancement for successful aging and preventing AD}

The highest risk factor for developing sporadic late-onset forms of the $\mathrm{AD}$ is aging [98]. The hippocampus is one of the brain regions most severely affected in the $\mathrm{AD}$, which is also a region in the brain containing neural stem cell (NSC) niches that add new neurons to the hippocampal circuitry throughout life. Within NSC niches, a subclass of slowly dividing cells expressing markers such as glial fibrillary acidic protein (GFAP), sex determining region Y-box 2 (Sox-2), brain lipid-binding protein, nestin, vimentin, and Musashi-1 are the NSCs or Type 1 cells [99-102]. When these cells divide, they display asymmetric division to maintain self-renewal as well as generate transit amplifying cells or type 2 cells. Type 2 cells express Sox-2 and Mash1 but not GFAP. They occur in clusters and proliferate actively to produce a pool of doublecortin (DCX) expressing neuroblasts or Type 3 cells and some glia [99, 103]. The neuroblasts differentiate into mature dentate granule cells expressing neuron-specific nuclear antigen (NeuN), Prox-1 and calbindin. Newly born granule cells establish afferent connectivity with the axons coming from the entorhinal cortex and efferent connectivity with the CA3 pyramidal neurons. Although the extent of hippocampal neurogenesis in adult humans has been challenged recently [104], there is enough credible evidence to support the existence of neurogenesis in the adult and aged human hippocampus. These are evident from both 5'-bromodeoxyuridine labeling studies in cancer patients [105], large-scale carbon-dating studies [106], and postmortem hippocampal tissue studies from healthy men and women with age ranging from 14-79 years [107].

Studies in animal models have shown that hippocampal neurogenesis decreases during aging [100, 108-113], and the overall decrease is exacerbated in the AD. The precise mechanistic causes underlying agerelated decline in neurogenesis are unclear. Persistence of NSCs with increased quiescence and multiple changes in the microenvironment of NSC niches have been observed in rat models [100, 108, 114-117]. However, no decline was seen in the expression of multiple genes essential for NSC proliferation and neurogenesis in the dentate gyrus [118]. Overall, it appears that age-related reductions in stem cell mitogenic factors, microvasculature and cerebral blood flow, and low-grade inflammation influence reduced neurogenesis in aging because increased neurogenesis could be obtained through interventional strategies that upregulate the concentration of NSC mitogenic factors [110, 119-121] or improve the microvasculature density and diminish inflammation [30]. A recent study investigated the effect of age on NSCs and neurogenesis in the senescence-accelerated mouse prone 
8 (SAMP8) strain, which is a non-transgenic short-lived strain that spontaneously develops a pathological profile similar to that of the AD [98]. SAMP8 mice displayed an accelerated loss of the NSCs that coincided with an enhanced canonical bone morphogenetic protein (BMP) signaling and increased astroglial differentiation. Remarkably, blocking the dysregulation of the BMP pathway and its pro-gliogenic effect in vivo by intracranial delivery of the antagonist Noggin restored hippocampal NSC numbers, neurogenesis, and behavior in SAMP8 mice. These results re-enforce the thought that modulation of the local microenvironment of the NSCs counteracts hippocampal dysfunction in pathological aging.

Many studies had suggested earlier that normalization of the activity of NSCs and neurogenesis slows down the evolution of $\mathrm{AD}$ when such interventions were applied at the early stage of the disease. The successful stratagems were physical exercise or exposure to the enriched environment [122-125], inhibition of microglial activation [126], choline supplementation [127], curcumin treatment [128] or directed expression of Neurod1 in cycling hippocampal progenitors [129]. An elegant study published recently, in addition, demonstrated that hippocampal neurogenesis is impaired before the onset of AD pathology [130]. Importantly, this investigation revealed that voluntary physical exercise could provide considerable cognitive benefit in $5 \times \mathrm{FAD}$ mice, through enhancement of both hippocampal neurogenesis and brain-derived neurotrophic factor (BDNF). Interestingly, neither stimulation of hippocampal neurogenesis alone, nor exercise, in the absence of increased hippocampal neurogenesis, improved cognitive function. When the beneficial effects of exercise on hippocampal neurogenesis and BDNF augmentation were mimicked through genetic or pharmacological means, a similar cognitive improvement was seen in AD mice. Furthermore, suppression of hippocampal neurogenesis resulted in worsened cognitive performance and loss of preexisting dentate granule cells. Thus, pharmacological mimetics of exercise capable of enhancing both hippocampal neurogenesis and BDNF appear to be useful for improving cognitive function in the early stages of the AD [130]. In summary, combined neurogenesis and BDNF boost during adulthood and middle age may postpone aging, and prevent or delay the onset of the $\mathrm{AD}$. In this context, regular or intermittent physical exercise throughout life seems to be the best and an inexpensive and non-invasive approach for continually maintaining higher levels of hippocampal neurogenesis and BDNF to stave off the AD. Pharmacological interventions mimicking physical exercise may also be useful but need rigorous testing in clinical trials for any adverse side effects.

\section{Physical Exercise for Modulating Aging and Preventing Dementia}

The benefits of regular physical exercise (PE) for conserving the function of the cardiovascular, musculoskeletal and nervous systems are well known [131-135]. PE boosts blood flow to the working skeletal muscles by up to 100 -fold and moderately to the brain; whereas organs such as liver, kidney, and testes encounter diminished blood flow during PE [136]. Even with the variability in blood flow to different organs, all organs gain from regular PE. PE attenuates the age-associated waning of maximal oxygen uptake $\left(\mathrm{VO}_{2} \max \right)$, the production of reactive oxygen species (ROS) and functional weakening of various organs [137]. Moreover, PE curbs the age-related deterioration of the cellular housekeeping system such as the proteasome, autophagy, mitophagy, and DNA repair systems, which positively impact multiple organ functions [137]. PE also leads to increased mitochondrial levels in the brain, heart, liver, and kidney $[138,139]$. Thus, the PE-induced surge of maximal oxygen uptake aids organ functions including the effectiveness of antioxidant and repair systems and cellular housekeeping activities.

PE enhances immunity and modulates age-related immunosenescence. Immunosenescence is typified by the weakening of the immune system with alterations to innate and adaptive immunity [140-143]. Age-related changes affect the phenotype and function of immune cells, which can interfere with chemotaxis, intracellular killing, and the response of immune cells to pathogens. Immunosenescence contributes to the development of several age-related diseases including cardiovascular disease, $\mathrm{AD}$, and diabetes in older individuals, and increases the risk for developing autoimmune diseases and chronic infection [142]. Thus, PE can also prevent age-related diseases through tempering immunosenescence. The effects of PE may also be useful for normalizing immune system function in conditions such as multiple sclerosis [144].

PE profoundly promotes the brain function in animals and humans. The aging-related cognitive decline epitomizes a critical risk factor for the onset of dementia and is linked with global neurophysiological alterations [145]. Remarkably, PE delays the age-related cognitive decline. In animal models, PE has been shown to enhance memory and mood function, accompanied with increased neurogenesis, upregulation of multiple neurotrophic factors including BDNF and improved synaptic plasticity in the hippocampus [146-152]. PE also augments neurogenesis and BDNF and prevents cognitive dysfunction in AD mice [130]. Besides, PE results in secretion of multiple factors from peripheral organs such as skeletal muscle, liver and adipose tissue, which can also 
influence neuronal function. A recent study demonstrated that proteins secreted by skeletal muscle cells could upregulate the expression of DCX and beta-III tubulin (TuJ-1), markers of immature neurons [153], implying that factors secreted by skeletal muscle in response to PE contribute to PE-induced increased neurogenesis.

Thus, regular PE commencing from young or middle age appears to be a necessary lifestyle change for maintaining good health in old age. Since drugs that significantly prevent age-related cognitive decline are yet to be discovered, it is vital to start PE regimen early in life when the neural reserve is still adequate, to completely avoid or at least postpone the cognitive decline. However, the amount of PE required in young or middle age to maintain healthy cognitive function in old age is yet to be ascertained. Some previous clinical trials of PE showed positive effects on cognitive performance whereas other trials showed minimal or no positive impact. Nonetheless, it is believed that PE programs that are structured, individualized, and continue for longer durations preserve cognitive performance in older adults $[154,155]$. Indeed, a recent clinical trial suggested that exercising for at least 52 hours over a six months duration is associated with improved cognitive performance in older adults with or without cognitive impairment [156]. Another study showed that combined physical and cognitive activity improves or maintains cognitive and physical performance in older individuals diagnosed with mild cognitive impairment (MCI), especially the amnestic type [157]. Clinical trials on the effects of various exercises on the prevention of the AD suggested that long-term physical activity with a multicomponent cognitive intervention improves cognitive function in patients with $\mathrm{AD}$ [158]. Overall, the results imply that, after the onset of MCI or early AD, PE intervention alone may not be sufficient but still has the promise to improve function when combined with adequate cognitive activity.

\section{Promising antioxidants and herbals for promoting successful aging}

Oxidative stress has a significant influence in the development of many age-related diseases, which include arthritis, diabetes, dementia, stroke, cancer, atherosclerosis, vascular diseases, obesity, osteoporosis, and metabolic syndromes [159-164]. Reactive oxygen species (ROS) are generated within the biological system to regulate cellular activities such as cell survival, stressor responses, ion channels, and inflammation [165, 166]. However, the elevation of ROS is linked to the onset and progression of aging. Particularly, ROS is believed to exacerbate the progression of age-related diseases via oxidative damage and interaction with mitochondria [167, 168]. Multiple studies imply that transient or physiological reactive oxygen species (ROS) generated by nicotinamide adenine dinucleotide phosphate (NADPH) oxidases operate as a redox signal to restore cellular homeostasis [169]. Typically, the competence to recreate cellular homeostasis gradually wanes during aging. However, long-lived animals display an ability to re-establish cellular homeostasis, which promotes healthy aging. Therefore, strategies that control NADPH oxidase activity for local and physiological redox signaling are likely to be useful for promoting healthy aging [169].

Older adults are more susceptible to oxidative stress due to a reduction in the efficiency of their endogenous antioxidant systems [170]. The heart and brain, with restricted cell renewal rate and excessive amounts of oxygen intake, are especially susceptible to this phenomenon. Typically, an inverse relationship has been observed between plasma antioxidant levels and the onset and progression of several diseases, which include cardiovascular disease [171], diabetes [172], and neurological disorders [173]. Emerging research suggests that natural antioxidants can control the autoxidation by interrupting the propagation of free radicals or by inhibiting the formation of free radicals. Through such actions, antioxidants reduce oxidative stress, improve immune function, and increase healthy longevity [164]. Antioxidants are capable of scavenging the species that initiate the peroxidation, breaking the autoxidative chain reaction, quenching free radicals, and preventing the formation of peroxides [174]. Therefore, dietary supplementation with antioxidants has received considerable interest in combating aging. This approach is also consistent with the free radical theory of aging $[175,176]$ that lowering the global level of ROS in the body would retard aging, increase lifespan, and prevent and treat aging-associated diseases [170, 177]. However, clinical trials with antioxidants in the elderly population have reported inconsistent findings [170]. The most promising antioxidants currently in clinical trials for treating cognitive dysfunction in aging and $\mathrm{AD}$ include resveratrol (RESV) and curcumin (CUR).

Regarding RESV, a clinical trial reported that 4months of RESV treatment in middle-aged men with metabolic syndrome increased muscle turnover, lipid metabolism, and accumulation of long-chain saturated, monounsaturated, and polyunsaturated free fatty acids, and produced beneficial alterations in gut microbiota [178]. Another clinical trial showed that incorporation of RESV to standard antihypertensive treatment is efficient for reducing blood pressure to normal levels, without the need for additional antihypertensive drugs [179]. This study also implied prevention of liver damage with RESV intake, based on lower levels of hepatic enzyme glutamate-pyruvate transaminase in the serum. Additional clinical trials have shown that RESV treatment improved 
memory performance allied with enhanced functional connectivity between the hippocampus and the medial prefrontal cortex in healthy overweight elderly individuals [180]. RESV has also been shown to strengthen neurovascular coupling and cognitive performance in type 2 diabetes patients [181]. Besides, in individuals with mild to a moderate AD, RESV treatment modulated amyloid $\beta-40$ levels in both plasma and cerebrospinal fluid, in comparison to the placebo-treated group [182].

CUR was tested in a randomized clinical trial comprising the healthy elderly population. In this study, improved sustained attention and working memory was observed with acute CUR administration, and enhanced mood and reduced fatigue were seen with a chronic treatment [183]. Another recent clinical trial reported that daily oral ingestion of a bioavailable and safe form of CUR improves memory performance over 18 months in middle-aged and older non-demented adults [184]. Moreover, this study suggested that daily oral CUR consumption may lead to less neuropathological accumulation in the amygdala and the hypothalamus [184]. Thus, based on the results of clinical trials performed, it appears that both RESV and CUR are safe, well-tolerated and beneficial with minimal side effects. Nonetheless, detailed, long-term, larger clinical trials are needed to fully understand the efficacy of RESV and CUR for improving cognitive function in elderly people afflicted with MCI or early stage of the AD.

Several herbs or other plant products used in Chinese medicine have also been suggested to promote health and longevity [185-191]. Among these, a Chinese herb named Astragalus membranaceus (Huangqi) has recently been proposed to have robust antiaging activity [186]. Astragalus membranaceus is a prime healing herb included in many herbal formulations in the practice of conventional Chinese medication to treat a variety of diseases. It is also marketed as a life-extending tonic for humans in China [186]. The significant components of Astragalus membranaceus are polysaccharides, flavonoids, and saponins. The components of Astragalus membranaceus has been shown to increase telomerase activity, and mediate antioxidant, anti-inflammatory, immunoregulatory, anticancer, hypolipidemic, antihyperglycemic, hepatoprotective, expectorant, and diuretic effects [186]. An extract of the dried root of Astragalus membranaceus, called TA-65, has been reported to promote considerable positive effects on the immune system. Thus, Astragalus membranaceus may be suitable as a dietary supplement for combating vascular aging, brain aging, and cancer. However, rigorous doubleblind, placebo-controlled clinical trials will be required to validate the efficacy of this herbal medicine for combating aging or $\mathrm{AD}$.

\section{Stem cell therapy for promoting healthy brain aging and reversing $\mathrm{AD}$}

The efficacy of intracerebral transplantation or peripheral injection of a variety of stem cells including mesenchymal stem cells (MSCs), NSCs or glial-restricted progenitors (GRPs) has been examined in animal models to improve the function of the aging brain. A study by Hattiangady and associates demonstrated that grafting of NSCs or GRPs into the aging hippocampus leads to the stimulation of endogenous NSCs in the subgranular zone and results in increased production of new dentate granule cells [192]. This study provided the first demonstration that grafting of GRPs or NSCs is an attractive approach for improving neurogenesis in the aging hippocampus. Consistent with these findings, another study showed that implantation of a human NSC cell line (CTX0E03) into the ventricles of aged rats is also useful for increasing neurogenesis in the hippocampus [193]. Collectively, these results suggested that NSC grafting can promote regeneration in the aged brain through stimulation of endogenous neurogenesis.

A long-term study by Shetty and Hattiangady further revealed that the aged hippocampus could support robust engraftment and differentiation of cells derived from NSC grafts [194]. An interesting finding is that grafted NSCs showed an ability to establish neurogenic niches in nonneurogenic regions of the aged hippocampus. The occurrence of new neurogenic niches was evidenced through the derivation of new, immature neurons from graft-derived cells within graft cores located in the nonneurogenic regions even at three months after grafting. Sequential labeling with different birth-dating markers further confirmed that the immature neurons found within graft cores were indeed generated from graft-derived cells in the aged hippocampus. This phenomenon is beneficial if these niches can continuously produce new neurons and glia in the grafted hippocampus, as newly generated neurons and glia are expected to improve not only the microenvironment but also the plasticity and function of the aged hippocampus. Overall, these results have significance because the potential application of NSC grafting for treatment of neurodegenerative disorders at early stages of the disease progression and age-related impairments would mostly involve aged persons as recipients. Even so, further studies are essential to ascertain the functional implications of NSC grafting into the aged hippocampus and whether NSCs from other sources such as human induced pluripotent stem cells (hiPSCs) or human embryonic stem cells (hESCs) would exhibit similar behavior. Another study by Zhang and colleagues showed that retardation of aging and lifespan extension could be achieved in middle-aged mice through implantation of hypothalamic NSCs into the aged 
hypothalamic nucleus exhibiting inflammatory microenvironment [195]. The grafted NSCs regulated aging through the release of exosomal miRNAs in this study.

A few studies have also examined the effects of administration of MSCs in aging models. Transplantation of adipose tissue-derived MSCs (AD-MSCs) improved locomotor activity and cognitive function in the aged animals, in parallel with the recovery of acetylcholine levels in brain tissues [196]. Grafting of AD-MSCs also restored microtubule-associated protein 2 in the host brain, enhanced trk-B expression, and concentrations of BDNF and nerve growth factor. These results suggest that grafting of human ADMSCs can restore the physical and cognitive function of aged mice. In another study, Cao and colleagues examined the effects of clinical-grade human umbilical cord-derived MSCs on cognitive aging in a mouse model of aging induced by d-galactose [197]. Mice received intraperitoneal administration of MSCs once weekly for two weeks. Three months after the administration of MSCs, the hippocampal-dependent learning and memory were found to be improved in aged mice, and the synaptic plasticity was enhanced in the CA1 area of the aged hippocampus. Moreover, MSC administration improved dendritic spine density, postsynaptic density, and neurogenesis in the hippocampus. Additional analyses showed that beneficial effects of MSC administration were mediated through activation of mitogen-activated protein kinase (MAPK)ERK-CREB signaling pathway in the aged hippocampus. Overall, this study demonstrated that peripheral administration of umbilical cord-derived MSCs is beneficial for improving the function of the aged brain.

Stem cell therapy has been shown to mediate beneficial effects in several other age-related neurodegenerative disease models. First, a study by Blurton-Jones and associates showed that hippocampal NSC transplantation rescued the spatial learning and memory deficits in aged 3xTg-AD mice [198]. The cognitive function was improved without altering the pathology of the AD. Gain-of-function and loss-offunction studies revealed that the mechanism underlying a better cognitive function involved improved hippocampal synaptic density mediated by BDNF. These are evident from observations that recombinant BDNF mimicked the beneficial effects of NSC grafting whereas depletion of NSC-derived BDNF failed to improve cognitive function or restore hippocampal synaptic density. These results suggest that NSC grafting can ameliorate complex behavioral deficits associated with AD pathology via BDNF. In a follow-up study, the same research group showed that transplantation of research grade human NSCs is also effective for improving cognitive function in two complementary models of $\mathrm{AD}$
[199]. Grafted human NSCs in this study significantly increased synaptic and growth-associated markers in both 3xTg-AD and CaM/Tet-DTA mice. Again, improvements in aged $3 \times \mathrm{Tg}-\mathrm{AD}$ mice were not associated with altered $\mathrm{A} \beta$ or tau pathology. It appeared that human NSC transplantation improved cognitive function by enhancing endogenous synaptogenesis. Another study showed that grafting of NSCs into the brain of 12-month-old Tg2576 mice (a model of the AD) markedly improved both cognitive function with an enhanced clearance of $\beta$ amyloid, secretion of anti-inflammatory cytokines, stimulation of endogenous neurogenesis, and synapse formation [200]. However, similar NSC grafting into 15month-old $\mathrm{Tg} 2576$ mice (i.e., the age at which mice display memory loss) did not result in improved cognitive dysfunction or clearance of $\beta$-amyloid. Thus, NSC therapy in the AD seems to work when grafting is performed in the early stage of the $\mathrm{AD}$ (i.e., before the manifestation of memory dysfunction). In summary, grafting of NSCs, GRPs or MSCs has shown promise for improving regeneration and function of the aged or $\mathrm{AD}$ brain. However, clinical trials using human tissue-derived stem cells (i.e., NSCs, GRPs or MSCs derived from hiPSCs or hESCs) will be required for further advancements in this field.

In addition to stem cell grafting approach, activation of endogenous cells in some regions of the body has promise for mediating regeneration during aging. In a recent study, Chunhua Zhao and colleagues propose that activation of mesenchymal tissue system may be a key for regeneration during aging [201]. The authors propose that triple energizer, which is a name used in Chinese medicine, is the largest organ in the body consisting of all functional cells originated from the MSC system during the embryonic development. This concept elaborates the origin, function and the essence of triple-energizer from the perspective of the human organ system. The tripleenergizer originates from the intraembryonic coelom of the embryo, which is the mesenchymal tissue system composed of functional cells derived from mesodermal stem cells and the microenvironment. Among these cells, Flk1+ MSCs (also expressing CD44, CD29, CD105 and CD166 but not CD34, CD31, and Lin), which is a type of post-embryonic PSCs (PEPSCs), are capable of giving rise to cells of all three germ layers. This mesenchymal tissue system, closely linked with organs and tissues, plays a vital role in tissue homeostasis and aging. Besides, authors propose that this system is responsible for the proliferation and differentiation of stem cells in the body, the regeneration, and repair of tissues and organs, immunity, and regulation of a molecular network of cell metabolism in the tissue system [201, 248-249]. 


\section{Conclusions}

There are many anti-aging strategies in development. Some of which have shown considerable promise for slowing down aging or delaying the onset of age-related diseases. From multiple pre-clinical studies, it appears that upregulation of autophagy through autophagy enhancers, elimination of senescent cells using senolytics, transfusion of plasma from young blood, neurogenesis and BDNF enhancement through specific drugs are promising approaches to sustain normal health during aging and also to postpone age-related diseases such as the AD. However, these approaches will require critical assessment in clinical trials to determine their long-term efficacy and lack of adverse effects on the function of various tissues and organs. On the other hand, approaches such as different types of IF, regular PE, RESV, and CUR treatment are ready for large-scale clinical trials, as they are non-invasive, and seem to have minimal side-effects. Stem cell therapy, particularly the administration of NSCs, GRPs, and MSCs, has also shown promise for improving regeneration and function of the aged or $\mathrm{AD}$ brain. Nonetheless, advancement of stem cell therapy for promoting successful brain aging or reversing $\mathrm{AD}$ symptoms and pathology would require clinical trials for safety and efficacy using cells derived from hiPSCs or $\mathrm{hESCs}$, as these sources can provide an unlimited number of specific cell types needed for cell therapy in different conditions.

\section{Acknowledgments}

This work was supported by the Department of Defense grants (W81XWH-14-1-0558 and W81XWH-14-1-0572 to A.K.S.), the Department of Veterans Affairs Merit Award (I01BX000883 to A.K.S.), the Department of Veterans Affairs BLR\&D Research Career Scientist award (1IK6BX003612 to A.K.S.) and an R01 grant from the National Institutes of Health - National Institute of Neurological Disorders and Stroke (NIH-NINDS R01NS106907-01 to D.J.P. and A.K.S.).

\section{Department of Defense, Department of Veterans Affairs, and United States Government Disclaimer}

The contents of this article suggest the views of authors and do not represent the views of the Department of Defense, U.S. Department of Veterans Affairs, or the United States Government.

\section{References}

Gurau F, Baldoni S, Prattichizzo F, Espinosa E, Amenta F, Procopio AD, et al. (2018). Anti-senescence healthy aging. Ageing Res Rev, 46:14-31.

Aunan JR, Cho WC, Soreide K (2017). The Biology of Aging and Cancer: A Brief Overview of Shared and Divergent Molecular Hallmarks. Aging Dis, 8:628642.

[3] de Magalhaes JP, Stevens M, Thornton D (2017). The Business of Anti-Aging Science. Trends Biotechnol, 35:1062-1073

[4] Sun N, Youle RJ, Finkel T (2016). The Mitochondrial Basis of Aging. Mol Cell, 61:654-666.

[5] Szybinska A, Lesniak W (2017). P53 Dysfunction in Neurodegenerative Diseases - The Cause or Effect of Pathological Changes? Aging Dis, 8:506-518.

[6] Xu Z, Feng W, Shen Q, Yu N, Yu K, Wang S, et al. (2017). Rhizoma Coptidis and Berberine as a Natural Drug to Combat Aging and Aging-Related Diseases via Anti-Oxidation and AMPK Activation. Aging Dis, 8:760-777.

[7] Zamroziewicz MK, Paul EJ, Zwilling CE, Barbey AK (2017). Predictors of Memory in Healthy Aging: Polyunsaturated Fatty Acid Balance and Fornix White Matter Integrity. Aging Dis, 8:372-383.

[8] Zinger A, Cho WC, Ben-Yehuda A (2017). Cancer and Aging - the Inflammatory Connection. Aging Dis, 8:611-627.

[9] Stambler I (2017). Recognizing Degenerative Aging as a Treatable Medical Condition: Methodology and Policy. Aging Dis, 8:583-589.

[10] Chakrabarti S, Mohanakumar KP (2016). Aging and Neurodegeneration: A Tangle of Models and Mechanisms. Aging Dis, 7:111-113.

[11] Konar A, Singh P, Thakur MK (2016). Age-associated Cognitive Decline: Insights into Molecular Switches and Recovery Avenues. Aging Dis, 7:121-129.

[12] de Magalhaes JP (2012). Programmatic features of aging originating in development: aging mechanisms beyond molecular damage? FASEB J, 26:4821-4826.

[13] Kenyon CJ (2010). The genetics of ageing. Nature, 464:504-512.

[14] Tacutu R, Craig T, Budovsky A, Wuttke D, Lehmann G, Taranukha D, et al. (2013). Human Ageing Genomic Resources: integrated databases and tools for the biology and genetics of ageing. Nucleic Acids Res, 41:D1027-1033.

[15] Bagherniya M, Butler AE, Barreto GE, Sahebkar A (2018). The effect of fasting or calorie restriction on autophagy induction: A review of the literature. Ageing Res Rev, 47:183-197.

[16] Redmann M, Darley-Usmar V, Zhang J (2016). The Role of Autophagy, Mitophagy and Lysosomal Functions in Modulating Bioenergetics and Survival in the Context of Redox and Proteotoxic Damage: Implications for Neurodegenerative Diseases. Aging Dis, 7:150-162.

[17] Hansen M, Rubinsztein DC, Walker DW (2018). Autophagy as a promoter of longevity: insights from model organisms. Nat Rev Mol Cell Biol, 19:579-593. [18] Scrivo A, Bourdenx M, Pampliega O, Cuervo AM (2018). Selective autophagy as a potential therapeutic 
target for neurodegenerative disorders. Lancet Neurol, 17:802-815.

[19] Moors TE, Hoozemans JJ, Ingrassia A, Beccari T, Parnetti L, Chartier-Harlin MC, et al. (2017). Therapeutic potential of autophagy-enhancing agents in Parkinson's disease. Mol Neurodegener, 12:11.

[20] Li Y, Wang K, Zhou K, Guo W, Dai B, Liang Y, et al. (2018). Novel D-A-D based near-infrared probes for the detection of beta-amyloid and Tau fibrils in Alzheimer's disease. Chem Commun (Camb), 54:8717-8720.

[21] Hamano T, Hayashi K, Shirafuji N, Nakamoto Y (2018). The Implications of Autophagy in Alzheimer's Disease. Curr Alzheimer Res, 15:1283-1296.

[22] Arensman MD, Eng CH (2018). Self-Digestion for Lifespan Extension: Enhanced Autophagy Delays Aging. Mol Cell, 71:485-486.

[23] Fernandez AF, Sebti S, Wei Y, Zou Z, Shi M, McMillan KL, et al. (2018). Disruption of the beclin 1-BCL2 autophagy regulatory complex promotes longevity in mice. Nature, 558:136-140.

[24] Shamalnasab M, Gravel SP, St-Pierre J, Breton L, Jager S, Aguilaniu H (2018). A salicylic acid derivative extends the lifespan of Caenorhabditis elegans by activating autophagy and the mitochondrial unfolded protein response. Aging Cell:e12830.

[25] Gelino S, Chang JT, Kumsta C, She X, Davis A, Nguyen C, et al. (2016). Intestinal Autophagy Improves Healthspan and Longevity in C. elegans during Dietary Restriction. PLoS Genet, 12:e1006135.

[26] Madeo F, Zimmermann A, Maiuri MC, Kroemer G (2015). Essential role for autophagy in life span extension. J Clin Invest, 125:85-93.

[27] Shakeri A, Cicero AFG, Panahi Y, Mohajeri M, Sahebkar A (2018). Curcumin: A naturally occurring autophagy modulator. J Cell Physiol. Sep 21, [Epub ahead of print].

[28] Revuelta M, Matheu A (2017). Autophagy in stem cell aging. Aging Cell, 16:912-915.

[29] Chung JH, Manganiello V, Dyck JR (2012). Resveratrol as a calorie restriction mimetic: therapeutic implications. Trends Cell Biol, 22:546-554

[30] Kodali M, Parihar VK, Hattiangady B, Mishra V, Shuai B, Shetty AK (2015). Resveratrol prevents agerelated memory and mood dysfunction with increased hippocampal neurogenesis and microvasculature, and reduced glial activation. Sci Rep, 5:8075.

[31] Morselli E, Galluzzi L, Kepp O, Criollo A, Maiuri MC, Tavernarakis N, et al. (2009). Autophagy mediates pharmacological lifespan extension by spermidine and resveratrol. Aging (Albany NY), 1:961-970.

[32] Shetty AK (2011). Promise of resveratrol for easing status epilepticus and epilepsy. Pharmacol Ther, 131:269-286.

[33] Eisenberg T, Abdellatif M, Schroeder S, Primessnig U, Stekovic S, Pendl T, et al. (2016). Cardioprotection and lifespan extension by the natural polyamine spermidine. Nat Med, 22:1428-1438.

[34] Madeo F, Carmona-Gutierrez D, Kepp O, Kroemer G (2018). Spermidine delays aging in humans. Aging
(Albany NY), 10:2209-2211.

Ren J, Zhang Y (2018). Targeting Autophagy in Aging and Aging-Related Cardiovascular Diseases. Trends Pharmacol Sci, 39:1064-1076.

[36] Zhang L, Hu T, Amombo E, Wang G, Xie Y, Fu J (2017). The Alleviation of Heat Damage to Photosystem II and Enzymatic Antioxidants by Exogenous Spermidine in Tall Fescue. Front Plant Sci, 8:1747.

[37] Bussian TJ, Aziz A, Meyer CF, Swenson BL, van Deursen JM, Baker DJ (2018). Clearance of senescent glial cells prevents tau-dependent pathology and cognitive decline. Nature, 562:578-582.

[38] Kirkland JL, Tchkonia T (2017). Cellular Senescence: A Translational Perspective. EBioMedicine, 21:21-28.

[39] Sun H, Paixao L, Oliva JT, Goparaju B, Carvalho DZ, van Leeuwen $\mathrm{KG}$, et al. (2018). Brain age from the electroencephalogram of sleep. Neurobiol Aging, 74:112-120.

[40] Wei W, Ji S (2018). Cellular senescence: Molecular mechanisms and pathogenicity. J Cell Physiol, 233:9121-9135.

[41] Schmitt R (2017). Senotherapy: growing old and staying young? Pflugers Arch, 469:1051-1059.

[42] von Kobbe C (2018). Cellular senescence: a view throughout organismal life. Cell Mol Life Sci, 75:3553-3567.

[43] Musi N, Valentine JM, Sickora KR, Baeuerle E, Thompson CS, Shen Q, et al. (2018). Tau protein aggregation is associated with cellular senescence in the brain. Aging Cell:e12840.

[44] Chang R, Geng Z, Zhu Q, Song Z, Wang Y (2017). Proton magnetic resonance spectroscopy reveals significant decline in the contents of $\mathrm{N}$ acetylaspartylglutamate in the hippocampus of aged healthy subjects. Arch Med Sci, 13:124-137.

[45] Kirkland JL, Tchkonia T, Zhu Y, Niedernhofer LJ, Robbins PD (2017). The Clinical Potential of Senolytic Drugs. J Am Geriatr Soc, 65:2297-2301.

[46] Zhu Z, Yang F, Li D, Zhou L, Liu Y, Zhang Y, et al. (2017). Age-related reduction of adaptive brain response during semantic integration is associated with gray matter reduction. PLoS One, 12:e0189462.

[47] Scudellari M (2015). Ageing research: Blood to blood. Nature, 517:426-429.

[48] Fan L, Fu D, Hong J, Huang H, He W, Zeng F, et al. (2018). Prognostic Significance of Blood Transfusion in Elderly Patients with Primary Diffuse Large B-Cell Lymphoma. Biomed Res Int, 2018:6742646.

[49] Castellano JM (2018). Blood-Based Therapies to Combat Aging. Gerontology:1-6.

[50] Conese M, Carbone A, Beccia E, Angiolillo A (2017). The Fountain of Youth: A Tale of Parabiosis, Stem Cells, and Rejuvenation. Open Med (Wars), 12:376383.

[51] Katsimpardi L, Litterman NK, Schein PA, Miller CM, Loffredo FS, Wojtkiewicz GR, et al. (2014). Vascular and neurogenic rejuvenation of the aging mouse brain by young systemic factors. Science, 344:630-634. [52] Villeda SA, Luo J, Mosher KI, Zou B, Britschgi M, 
Bieri G, et al. (2011). The ageing systemic milieu negatively regulates neurogenesis and cognitive function. Nature, 477:90-94.

[53] Villeda SA, Plambeck KE, Middeldorp J, Castellano JM, Mosher KI, Luo J, et al. (2014). Young blood reverses age-related impairments in cognitive function and synaptic plasticity in mice. Nat Med, 20:659-663. Khoury R, Ghossoub E (2018). Young blood products: emerging treatment for Alzheimer's disease? Neural Regen Res, 13:624-627.

[55] Sinha I, Sinha-Hikim AP, Wagers AJ, Sinha-Hikim I (2014). Testosterone is essential for skeletal muscle growth in aged mice in a heterochronic parabiosis model. Cell Tissue Res, 357:815-821.

[56] Loffredo FS, Steinhauser ML, Jay SM, Gannon J, Pancoast JR, Yalamanchi P, et al. (2013). Growth differentiation factor 11 is a circulating factor that reverses age-related cardiac hypertrophy. Cell, 153:828-839.

[57] Ozek C, Krolewski RC, Buchanan SM, Rubin LL (2018). Growth Differentiation Factor 11 treatment leads to neuronal and vascular improvements in the hippocampus of aged mice. Sci Rep, 8:17293.

[58] Middeldorp J, Lehallier B, Villeda SA, Miedema SS, Evans E, Czirr E, et al. (2016). Preclinical Assessment of Young Blood Plasma for Alzheimer Disease. JAMA Neurol, 73:1325-1333.

[59] Aicardi G (2018). Young Blood Plasma Administration to Fight Alzheimer's Disease? Rejuvenation Res, 21:178-181.

[60] Pandey S, Vyas GN (2012). Adverse effects of plasma transfusion. Transfusion, 52 Suppl 1:65S-79S.

[61] Hofmann B (2018). Young Blood Rejuvenates Old Bodies: A Call for Reflection when Moving from Mice to Men. Transfus Med Hemother, 45:67-71.

[62] Hanjani NA, Vafa M (2018). Protein Restriction, Epigenetic Diet, Intermittent Fasting as New Approaches for Preventing Age-associated Diseases. Int J Prev Med, 9:58.

[63] Kapahi P, Kaeberlein M, Hansen M (2017). Dietary restriction and lifespan: Lessons from invertebrate models. Ageing Res Rev, 39:3-14.

[64] Mattson MP, Arumugam TV (2018). Hallmarks of Brain Aging: Adaptive and Pathological Modification by Metabolic States. Cell Metab, 27:1176-1199.

[65] Van Cauwenberghe C, Van Broeckhoven C, Sleegers $\mathrm{K}$ (2016). The genetic landscape of Alzheimer disease: clinical implications and perspectives. Genet Med, 18:421-430.

[66] Kim SY, Sim S, Park B, Kong IG, Kim JH, Choi HG (2016). Dietary Habits Are Associated With School Performance in Adolescents. Medicine (Baltimore), 95:e3096.

[67] Balasubramanian P, Howell PR, Anderson RM (2017). Aging and Caloric Restriction Research: A Biological Perspective With Translational Potential. EBioMedicine, 21:37-44.

[68] Ingram DK, de Cabo R (2017). Calorie restriction in rodents: Caveats to consider. Ageing Res Rev, 39:1528.
[69] Suzuki S, Yamatoya H, Sakai M, Kataoka A, Furushiro M, Kudo S (2001). Oral administration of soybean lecithin transphosphatidylated phosphatidylserine improves memory impairment in aged rats. J Nutr, 131:2951-2956.

[70] Most J, Tosti V, Redman LM, Fontana L (2017). Calorie restriction in humans: An update. Ageing Res Rev, 39:36-45.

[71] Pifferi F, Terrien J, Marchal J, Dal-Pan A, Djelti F, Hardy I, et al. (2018). Caloric restriction increases lifespan but affects brain integrity in grey mouse lemur primates. Commun Biol, 1:30.

[72] Fabbiano S, Suarez-Zamorano N, Chevalier C, Lazarevic V, Kieser S, Rigo D, et al. (2018). Functional Gut Microbiota Remodeling Contributes to the Caloric Restriction-Induced Metabolic Improvements. Cell Metab. Aug 24, [Epub ahead of print].

[73] Hadad N, Unnikrishnan A, Jackson JA, Masser DR, Otalora L, Stanford DR, et al. (2018). Caloric restriction mitigates age-associated hippocampal differential CG and non-CG methylation. Neurobiol Aging, 67:53-66.

[74] Bondolfi L, Ermini F, Long JM, Ingram DK, Jucker M (2004). Impact of age and caloric restriction on neurogenesis in the dentate gyrus of $\mathrm{C} 57 \mathrm{BL} / 6$ mice. Neurobiol Aging, 25:333-340.

Morgan AH, Andrews ZB, Davies JS (2017). Less is more: Caloric regulation of neurogenesis and adult brain function. J Neuroendocrinol, 29: e12512.

[76] Dal-Pan A, Pifferi F, Marchal J, Picq JL, Aujard F, Consortium R (2011). Cognitive performances are selectively enhanced during chronic caloric restriction or resveratrol supplementation in a primate. PLoS One, 6:e16581.

[77] Horie NC, Serrao VT, Simon SS, Gascon MR, Dos Santos AX, Zambone MA, et al. (2016). Cognitive Effects of Intentional Weight Loss in Elderly Obese Individuals With Mild Cognitive Impairment. J Clin Endocrinol Metab, 101:1104-1112.

[78] Parikh PK, Troyer AK, Maione AM, Murphy KJ (2016). The Impact of Memory Change on Daily Life in Normal Aging and Mild Cognitive Impairment. Gerontologist, 56:877-885.

[79] Wahl D, Coogan SC, Solon-Biet SM, de Cabo R, Haran JB, Raubenheimer D, et al. (2017). Cognitive and behavioral evaluation of nutritional interventions in rodent models of brain aging and dementia. Clin Interv Aging, 12:1419-1428.

[80] Mattson MP, Longo VD, Harvie M (2017). Impact of intermittent fasting on health and disease processes. Ageing Res Rev, 39:46-58.

[81] Stockman MC, Thomas D, Burke J, Apovian CM (2018). Intermittent Fasting: Is the Wait Worth the Weight? Curr Obes Rep, 7:172-185.

[82] Ahmet I, Wan R, Mattson MP, Lakatta EG, Talan M (2005). Cardioprotection by intermittent fasting in rats. Circulation, 112:3115-3121.

[83] Zuo L, He F, Tinsley GM, Pannell BK, Ward E, Arciero PJ (2016). Comparison of High-Protein, 
Intermittent Fasting Low-Calorie Diet and Heart Healthy Diet for Vascular Health of the Obese. Front Physiol, 7:350.

[84] Joslin PMN, Bell RK, Swoap SJ (2017). Obese mice on a high-fat alternate-day fasting regimen lose weight and improve glucose tolerance. J Anim Physiol Anim Nutr (Berl), 101:1036-1045.

[85] Horne BD, Muhlestein JB, Anderson JL (2015). Health effects of intermittent fasting: hormesis or harm? A systematic review. Am J Clin Nutr, 102:464470.

[86] Li L, Wang Z, Zuo Z (2013). Chronic intermittent fasting improves cognitive functions and brain structures in mice. PLoS One, 8:e66069.

[87] Singh P, Konar A, Kumar A, Srivas S, Thakur MK (2015). Hippocampal chromatin-modifying enzymes are pivotal for scopolamine-induced synaptic plasticity gene expression changes and memory impairment. J Neurochem, 134:642-651.

[88] Jeong JH, Yu KS, Bak DH, Lee JH, Lee NS, Jeong YG, et al. (2016). Intermittent fasting is neuroprotective in focal cerebral ischemia by minimizing autophagic flux disturbance and inhibiting apoptosis. Exp Ther Med, 12:3021-3028.

[89] Manzanero S, Erion JR, Santro T, Steyn FJ, Chen C, Arumugam TV, et al. (2014). Intermittent fasting attenuates increases in neurogenesis after ischemia and reperfusion and improves recovery. J Cereb Blood Flow Metab, 34:897-905.

[90] Kim YK, Koppula S, Shim DW, In EJ, Kwak SB, Kim MK, et al. (2018). Inhibitory Effect and Mechanism of Arctium lappa Extract on NLRP3 Inflammasome Activation. Evid Based Complement Alternat Med, 2018:6346734

[91] Vasconcelos AR, Kinoshita PF, Yshii LM, Marques Orellana AM, Bohmer AE, de Sa Lima L, et al. (2015). Effects of intermittent fasting on age-related changes on $\mathrm{Na}, \mathrm{K}-\mathrm{ATPase}$ activity and oxidative status induced by lipopolysaccharide in rat hippocampus. Neurobiol Aging, 36:1914-1923.

[92] Vasconcelos AR, Yshii LM, Viel TA, Buck HS, Mattson MP, Scavone C, et al. (2014). Intermittent fasting attenuates lipopolysaccharide-induced neuroinflammation and memory impairment. J Neuroinflammation, 11:85.

[93] Halagappa VK, Guo Z, Pearson M, Matsuoka Y, Cutler RG, Laferla FM, et al. (2007). Intermittent fasting and caloric restriction ameliorate age-related behavioral deficits in the triple-transgenic mouse model of Alzheimer's disease. Neurobiol Dis, 26:212 220.

[94] Zhang J, Wu L, Chen J, Lin S, Cai D, Chen C, et al. (2018). Downregulation of MicroRNA 29a/b exacerbated diabetic retinopathy by impairing the function of Muller cells via Forkhead box protein O4. Diab Vasc Dis Res, 15:214-222.

[95] Catterson JH, Khericha M, Dyson MC, Vincent AJ, Callard R, Haveron SM, et al. (2018). Short-Term, Intermittent Fasting Induces Long-Lasting Gut Health and TOR-Independent Lifespan Extension. Curr Biol,
28:1714-1724 e1714.

[96] Mihaylova MM, Cheng CW, Cao AQ, Tripathi S, Mana MD, Bauer-Rowe KE, et al. (2018). Fasting Activates Fatty Acid Oxidation to Enhance Intestinal Stem Cell Function during Homeostasis and Aging. Cell Stem Cell, 22:769-778 e764.

[97] Harder-Lauridsen NM, Rosenberg A, Benatti FB, Damm JA, Thomsen C, Mortensen EL, et al. (2017). Ramadan model of intermittent fasting for $28 \mathrm{~d}$ had no major effect on body composition, glucose metabolism, or cognitive functions in healthy lean men. Nutrition, 37:92-103.

[98] Diaz-Moreno M, Armenteros T, Gradari S, Hortiguela R, Garcia-Corzo L, Fontan-Lozano A, et al. (2018). Noggin rescues age-related stem cell loss in the brain of senescent mice with neurodegenerative pathology. Proc Natl Acad Sci U S A, 115:11625-11630.

[99] Encinas JM, Michurina TV, Peunova N, Park JH, Tordo J, Peterson DA, et al. (2011). Division-coupled astrocytic differentiation and age-related depletion of neural stem cells in the adult hippocampus. Cell Stem Cell, 8:566-579.

[100] Hattiangady B, Shetty AK (2008). Aging does not alter the number or phenotype of putative stem/progenitor cells in the neurogenic region of the hippocampus. Neurobiol Aging, 29:129-147.

[101] Ihrie RA, Alvarez-Buylla A (2008). Cells in the astroglial lineage are neural stem cells. Cell Tissue Res, 331:179-191.

[102] Seri B, Garcia-Verdugo JM, McEwen BS, AlvarezBuylla A (2001). Astrocytes give rise to new neurons in the adult mammalian hippocampus. J Neurosci, 21:7153-7160.

[103] Hsieh J (2012). Orchestrating transcriptional control of adult neurogenesis. Genes Dev, 26:1010-1021.

[104] Sorrells SF, Paredes MF, Cebrian-Silla A, Sandoval K, Qi D, Kelley KW, et al. (2018). Human hippocampal neurogenesis drops sharply in children to undetectable levels in adults. Nature, 555:377-381.

[105] Eriksson PS, Perfilieva E, Bjork-Eriksson T, Alborn AM, Nordborg C, Peterson DA, et al. (1998). Neurogenesis in the adult human hippocampus. Nat Med, 4:1313-1317.

[106] Spalding KL, Bergmann O, Alkass K, Bernard S, Salehpour M, Huttner HB, et al. (2013). Dynamics of hippocampal neurogenesis in adult humans. Cell, 153:1219-1227.

[107] Boldrini M, Fulmore CA, Tartt AN, Simeon LR, Pavlova I, Poposka V, et al. (2018). Human Hippocampal Neurogenesis Persists throughout Aging. Cell Stem Cell, 22:589-599 e585.

[108] Drapeau E, Nora Abrous D (2008). Stem cell review series: role of neurogenesis in age-related memory disorders. Aging Cell, 7:569-589.

[109] Kuhn HG, Dickinson-Anson H, Gage FH (1996). Neurogenesis in the dentate gyrus of the adult rat: agerelated decrease of neuronal progenitor proliferation. $\mathrm{J}$ Neurosci, 16:2027-2033.

[110] Rai KS, Hattiangady B, Shetty AK (2007). Enhanced production and dendritic growth of new dentate 
granule cells in the middle-aged hippocampus following intracerebroventricular FGF-2 infusions. Eur J Neurosci, 26:1765-1779.

[111] Rao MS, Hattiangady B, Abdel-Rahman A, Stanley DP, Shetty AK (2005). Newly born cells in the ageing dentate gyrus display normal migration, survival and neuronal fate choice but endure retarded early maturation. Eur J Neurosci, 21:464-476.

[112] Rao MS, Hattiangady B, Shetty AK (2006). The window and mechanisms of major age-related decline in the production of new neurons within the dentate gyrus of the hippocampus. Aging Cell, 5:545-558.

[113] Shetty AK, Hattiangady B, Rao MS, Shuai B (2012). Neurogenesis response of middle-aged hippocampus to acute seizure activity. PLoS One, 7:e43286.

[114] Sontag CJ, Uchida N, Cummings BJ, Anderson AJ (2014). Injury to the spinal cord niche alters the engraftment dynamics of human neural stem cells. Stem Cell Reports, 2:620-632.

[115] Chadashvili T, Peterson DA (2006). Cytoarchitecture of fibroblast growth factor receptor 2 (FGFR-2) immunoreactivity in astrocytes of neurogenic and nonneurogenic regions of the young adult and aged rat brain. J Comp Neurol, 498:1-15.

[116] Shetty AK, Hattiangady B, Shetty GA (2005). Stem/progenitor cell proliferation factors FGF-2, IGF1 , and VEGF exhibit early decline during the course of aging in the hippocampus: role of astrocytes. Glia, 51:173-186.

[117] Hattiangady B, Shetty AK (2012). Neural stem cell grafting counteracts hippocampal injury-mediated impairments in mood, memory, and neurogenesis. Stem Cells Transl Med, 1:696-708.

[118] Shetty GA, Hattiangady B, Shetty AK (2013). Neural stem cell- and neurogenesis-related gene expression profiles in the young and aged dentate gyrus. Age (Dordr), 35:2165-2176.

[119] Lichtenwalner RJ, Forbes ME, Bennett SA, Lynch CD, Sonntag WE, Riddle DR (2001). Intracerebroventricular infusion of insulin-like growth factor-I ameliorates the age-related decline in hippocampal neurogenesis. Neuroscience, 107:603613.

[120] Jin K, Sun Y, Xie L, Batteur S, Mao XO, Smelick C, et al. (2003). Neurogenesis and aging: FGF-2 and HBEGF restore neurogenesis in hippocampus and subventricular zone of aged mice. Aging Cell, 2:175183.

[121] Enwere E, Shingo T, Gregg C, Fujikawa H, Ohta S, Weiss S (2004). Aging results in reduced epidermal growth factor receptor signaling, diminished olfactory neurogenesis, and deficits in fine olfactory discrimination. J Neurosci, 24:8354-8365.

[122] Costa DA, Cracchiolo JR, Bachstetter AD, Hughes TF, Bales KR, Paul SM, et al. (2007). Enrichment improves cognition in AD mice by amyloid-related and unrelated mechanisms. Neurobiol Aging, 28:831844.

[123] Nichol K, Deeny SP, Seif J, Camaclang K, Cotman CW (2009). Exercise improves cognition and hippocampal plasticity in APOE epsilon4 mice. Alzheimers Dement, 5:287-294.

[124] Nichol KE, Parachikova AI, Cotman CW (2007). Three weeks of running wheel exposure improves cognitive performance in the aged $\mathrm{Tg} 2576$ mouse. Behav Brain Res, 184:124-132.

[125] Tapia-Rojas C, Aranguiz F, Varela-Nallar L, Inestrosa NC (2016). Voluntary Running Attenuates Memory Loss, Decreases Neuropathological Changes and Induces Neurogenesis in a Mouse Model of Alzheimer's Disease. Brain Pathol, 26:62-74.

[126] Biscaro B, Lindvall O, Tesco G, Ekdahl CT, Nitsch RM (2012). Inhibition of microglial activation protects hippocampal neurogenesis and improves cognitive deficits in a transgenic mouse model for Alzheimer's disease. Neurodegener Dis, 9:187-198.

[127] Velazquez R, Ash JA, Powers BE, Kelley CM, Strawderman M, Luscher ZI, et al. (2013). Maternal choline supplementation improves spatial learning and adult hippocampal neurogenesis in the Ts65Dn mouse model of Down syndrome. Neurobiol Dis, 58:92-101.

[128] Tiwari SK, Agarwal S, Seth B, Yadav A, Nair S, Bhatnagar P, et al. (2014). Curcumin-loaded nanoparticles potently induce adult neurogenesis and reverse cognitive deficits in Alzheimer's disease model via canonical Wnt/beta-catenin pathway. ACS Nano, 8:76-103.

[129] Richetin K, Leclerc C, Toni N, Gallopin T, Pech S, Roybon L, et al. (2015). Genetic manipulation of adult-born hippocampal neurons rescues memory in a mouse model of Alzheimer's disease. Brain, 138:440455.

[130] Choi SH, Bylykbashi E, Chatila ZK, Lee SW, Pulli B, Clemenson GD, et al. (2018). Combined adult neurogenesis and BDNF mimic exercise effects on cognition in an Alzheimer's mouse model. Science, 361.

[131] Booth J, Moseley GL, Schiltenwolf M, Cashin A, Davies M, Hubscher M (2017). Exercise for chronic musculoskeletal pain: A biopsychosocial approach. Musculoskeletal Care, 15:413-421.

[132] Gutierrez-Martinez L, Martinez RG, Gonzalez SA, Bolivar MA, Estupinan OV, Sarmiento OL (2018). Effects of a strategy for the promotion of physical activity in students from Bogota. Rev Saude Publica, 52:79.

[133] Mandolesi L, Polverino A, Montuori S, Foti F, Ferraioli G, Sorrentino P, et al. (2018). Effects of Physical Exercise on Cognitive Functioning and Wellbeing: Biological and Psychological Benefits. Front Psychol, 9:509.

[134] Ozemek C, Laddu DR, Lavie CJ, Claeys H, Kaminsky LA, Ross R, et al. (2018). An Update on the Role of Cardiorespiratory Fitness, Structured Exercise and Lifestyle Physical Activity in Preventing Cardiovascular Disease and Health Risk. Prog Cardiovasc Dis.

[135] Wang R, Holsinger RMD (2018). Exercise-induced brain-derived neurotrophic factor expression: Therapeutic implications for Alzheimer's dementia. 
Ageing Res Rev, 48:109-121.

[136] Radak Z, Chung HY, Koltai E, Taylor AW, Goto S (2008). Exercise, oxidative stress and hormesis. Ageing Res Rev, 7:34-42.

[137] Radak Z, Torma F, Berkes I, Goto S, Mimura T, Posa A, et al. (2018). Exercise effects on physiological function during aging. Free Radic Biol Med, S08915849(18): 32273-1.

[138] Boveris A, Navarro A (2008). Systemic and mitochondrial adaptive responses to moderate exercise in rodents. Free Radic Biol Med, 44:224-229.

[139] Marosi K, Bori Z, Hart N, Sarga L, Koltai E, Radak Z, et al. (2012). Long-term exercise treatment reduces oxidative stress in the hippocampus of aging rats. Neuroscience, 226:21-28.

[140] Campbell JP, Turner JE (2018). Debunking the Myth of Exercise-Induced Immune Suppression: Redefining the Impact of Exercise on Immunological Health Across the Lifespan. Front Immunol, 9:648.

[141] de Araujo AL, Silva LC, Fernandes JR, Benard G (2013). Preventing or reversing immunosenescence: can exercise be an immunotherapy? Immunotherapy, 5:879-893.

[142] Sellami M, Gasmi M, Denham J, Hayes LD, Stratton D, Padulo J, et al. (2018). Effects of Acute and Chronic Exercise on Immunological Parameters in the Elderly Aged: Can Physical Activity Counteract the Effects of Aging? Front Immunol, 9:2187.

[143] Turner JE (2016). Is immunosenescence influenced by our lifetime "dose" of exercise? Biogerontology, 17:581-602.

[144] Klaren RE, Sebastiao E, Chiu CY, Kinnett-Hopkins D, McAuley E, Motl RW (2016). Levels and Rates of Physical Activity in Older Adults with Multiple Sclerosis. Aging Dis, 7:278-284.

[145] Brem AK, Sensi SL (2018). Towards Combinatorial Approaches for Preserving Cognitive Fitness in Aging. Trends Neurosci, 41:885-897.

[146] van Praag H, Christie BR, Sejnowski TJ, Gage FH (1999). Running enhances neurogenesis, learning, and long-term potentiation in mice. Proc Natl Acad Sci U S A, 96:13427-13431.

[147] Marlatt MW, Potter MC, Lucassen PJ, van Praag H (2012). Running throughout middle-age improves memory function, hippocampal neurogenesis, and BDNF levels in female $\mathrm{C} 57 \mathrm{BL} / 6 \mathrm{~J}$ mice. Dev Neurobiol, 72:943-952.

[148] Kodali M, Megahed T, Mishra V, Shuai B, Hattiangady B, Shetty AK (2016). Voluntary Running ExerciseMediated Enhanced Neurogenesis Does Not Obliterate Retrograde Spatial Memory. J Neurosci, 36:8112-8122.

[149] Ma J, Wang J, Lv C, Pang J, Han B, Wang M, et al. (2017). The Role of Hippocampal Structural Synaptic Plasticity in Repetitive Transcranial Magnetic Stimulation to Improve Cognitive Function in Male SAMP8 Mice. Cell Physiol Biochem, 41:137-144.

[150] Cooper SB, Dring KJ, Morris JG, Sunderland C, Bandelow S, Nevill ME (2018). High intensity intermittent games-based activity and adolescents' cognition: moderating effect of physical fitness. BMC Public Health, 18:603.

[151] Liu PZ, Nusslock R (2018). Exercise-Mediated Neurogenesis in the Hippocampus via BDNF. Front Neurosci, 12:52.

[152] Kannangara TS, Lucero MJ, Gil-Mohapel J, Drapala RJ, Simpson JM, Christie BR, et al. (2011). Running reduces stress and enhances cell genesis in aged mice. Neurobiol Aging, 32:2279-2286.

[153] Moon HY, Javadi S, Stremlau M, Yoon KJ, Becker B, Kang SU, et al. (2018). Conditioned media from AICAR-treated skeletal muscle cells increases neuronal differentiation of adult neural progenitor cells. Neuropharmacology.

[154] Kirk-Sanchez NJ, McGough EL (2014). Physical exercise and cognitive performance in the elderly: current perspectives. Clin Interv Aging, 9:51-62.

[155] Mariolis A, Foscolou A, Tyrovolas S, Piscopo S, Valacchi G, Tsakountakis N, et al. (2016). Successful Aging among Elders Living in the Mani Continental Region vs. Insular Areas of the Mediterranean: the MEDIS Study. Aging Dis, 7:285-294.

[156] Gomes-Osman J, Cabral DF, Morris TP, McInerney K, Cahalin LP, Rundek T, et al. (2018). Exercise for cognitive brain health in aging: A systematic review for an evaluation of dose. Neurol Clin Pract, 8:257265.

[157] Shimada H, Makizako H, Doi T, Park H, Tsutsumimoto K, Verghese J, et al. (2018). Effects of Combined Physical and Cognitive Exercises on Cognition and Mobility in Patients With Mild Cognitive Impairment: A Randomized Clinical Trial. J Am Med Dir Assoc, 19:584-591.

[158] Shen Y, Li R (2016). What do we know from clinical trials on exercise and Alzheimer's disease? J Sport Health Sci, 5:397-399.

[159] Zhao M, Zhu P, Fujino M, Zhuang J, Guo H, Sheikh I, et al. (2016). Oxidative Stress in Hypoxic-Ischemic Encephalopathy: Molecular Mechanisms and Therapeutic Strategies. Int J Mol Sci, 17.

[160] Bellezza I (2018). Oxidative Stress in Age-Related Macular Degeneration: Nrf2 as Therapeutic Target. Front Pharmacol, 9:1280.

[161] Barrera G, Pizzimenti S, Daga M, Dianzani C, Arcaro A, Cetrangolo GP, et al. (2018). Lipid PeroxidationDerived Aldehydes, 4-Hydroxynonenal and Malondialdehyde in Aging-Related Disorders. Antioxidants (Basel), 7.

[162] Kloska D, Kopacz A, Piechota-Polanczyk A, Nowak WN, Dulak J, Jozkowicz A, et al. (2018). Nrf2 in aging - Focus on the cardiovascular system. Vascul Pharmacol.

[163] Liguori I, Russo G, Curcio F, Bulli G, Aran L, DellaMorte D, et al. (2018). Oxidative stress, aging, and diseases. Clin Interv Aging, 13:757-772.

[164] Tan BL, Norhaizan ME, Liew WP, Sulaiman Rahman H (2018). Antioxidant and Oxidative Stress: A Mutual Interplay in Age-Related Diseases. Front Pharmacol, 9:1162.

[165] Sesti F (2016). Oxidation of $\mathrm{K}(+)$ Channels in Aging 
and Neurodegeneration. Aging Dis, 7:130-135.

[166] Zuo L, Pannell BK (2015). Redox Characterization of Functioning Skeletal Muscle. Front Physiol, 6:338.

[167] Dias V, Junn E, Mouradian MM (2013). The role of oxidative stress in Parkinson's disease. J Parkinsons Dis, 3:461-491.

[168] Onyango IG, Dennis J, Khan SM (2016). Mitochondrial Dysfunction in Alzheimer's Disease and the Rationale for Bioenergetics Based Therapies. Aging Dis, 7:201-214.

[169] Ewald CY (2018). Redox Signaling of NADPH Oxidases Regulates Oxidative Stress Responses, Immunity and Aging. Antioxidants (Basel), 7.

[170] Conti V, Izzo V, Corbi G, Russomanno G, Manzo V, De Lise F, et al. (2016). Antioxidant Supplementation in the Treatment of Aging-Associated Diseases. Front Pharmacol, 7:24.

[171] Ciancarelli I, Di Massimo C, De Amicis D, Pistarini C, Tozzi Ciancarelli MG (2015). Uric acid and $\mathrm{Cu} / \mathrm{Zn}$ superoxide dismutase: potential strategies and biomarkers in functional recovery of post-acute ischemic stroke patients after intensive neurorehabilitation. Curr Neurovasc Res, 12:120-127.

[172] Opara EC, Abdel-Rahman E, Soliman S, Kamel WA, Souka S, Lowe JE, et al. (1999). Depletion of total antioxidant capacity in type 2 diabetes. Metabolism, 48:1414-1417.

[173] Schrag M, Mueller C, Zabel M, Crofton A, Kirsch WM, Ghribi O, et al. (2013). Oxidative stress in blood in Alzheimer's disease and mild cognitive impairment: a meta-analysis. Neurobiol Dis, 59:100-110.

[174] Gaschler MM, Stockwell BR (2017). Lipid peroxidation in cell death. Biochem Biophys Res Commun, 482:419-425.

[175] Harman D (1992). Free radical theory of aging: history. EXS, 62:1-10.

[176] Pomatto LCD, Davies KJA (2018). Adaptive homeostasis and the free radical theory of ageing. Free Radic Biol Med, 124:420-430.

[177] Sadowska-Bartosz I, Bartosz G (2014). Effect of antioxidants supplementation on aging and longevity. Biomed Res Int, 2014:404680.

[178] Korsholm AS, Kjaer TN, Ornstrup MJ, Pedersen SB (2017). Comprehensive Metabolomic Analysis in Blood, Urine, Fat, and Muscle in Men with Metabolic Syndrome: A Randomized, Placebo-Controlled Clinical Trial on the Effects of Resveratrol after Four Months' Treatment. Int J Mol Sci, 18: 554-573

[179] Theodotou M, Fokianos K, Mouzouridou A, Konstantinou C, Aristotelous A, Prodromou D, et al. (2017). The effect of resveratrol on hypertension: A clinical trial. Exp Ther Med, 13:295-301.

[180] Witte AV, Kerti L, Margulies DS, Floel A (2014). Effects of resveratrol on memory performance, hippocampal functional connectivity, and glucose metabolism in healthy older adults. J Neurosci, 34:7862-7870.

[181] Wong RH, Raederstorff D, Howe PR (2016). Acute Resveratrol Consumption Improves Neurovascular Coupling Capacity in Adults with Type 2 Diabetes
Mellitus. Nutrients, 8.

[182] Turner RS, Thomas RG, Craft S, van Dyck CH, Mintzer J, Reynolds BA, et al. (2015). A randomized, double-blind, placebo-controlled trial of resveratrol for Alzheimer disease. Neurology, 85:1383-1391.

[183] Cox KH, Pipingas A, Scholey AB (2015). Investigation of the effects of solid lipid curcumin on cognition and mood in a healthy older population. $\mathrm{J}$ Psychopharmacol, 29:642-651.

[184] Small GW, Siddarth P, Li Z, Miller KJ, Ercoli L, Emerson ND, et al. (2018). Memory and Brain Amyloid and Tau Effects of a Bioavailable Form of Curcumin in Non-Demented Adults: A Double-Blind, Placebo-Controlled 18-Month Trial. Am J Geriatr Psychiatry, 26:266-277.

[185] Yang Y, Ren C, Zhang Y, Wu X (2017). Ginseng: An Nonnegligible Natural Remedy for Healthy Aging. Aging Dis, 8:708-720.

[186] Liu P, Zhao H, Luo Y (2017). Anti-Aging Implications of Astragalus Membranaceus (Huangqi): A WellKnown Chinese Tonic. Aging Dis, 8:868-886.

[187] Wang J, Cao B, Zhao H, Feng J (2017). Emerging Roles of Ganoderma Lucidum in Anti-Aging. Aging Dis, 8:691-707.

[188] Wang N, Ji S, Zhang H, Mei S, Qiao L, Jin X (2017). Herba Cistanches: Anti-aging. Aging Dis, 8:740-759.

[189] Zhao H, Luo Y (2017). Traditional Chinese Medicine and Aging Intervention. Aging Dis, 8:688-690.

[190] Gao Y, Wei Y, Wang Y, Gao F, Chen Z (2017). Lycium Barbarum: A Traditional Chinese Herb and A Promising Anti-Aging Agent. Aging Dis, 8:778-791.

[191] Zuo W, Yan F, Zhang B, Li J, Mei D (2017). Advances in the Studies of Ginkgo Biloba Leaves Extract on Aging-Related Diseases. Aging Dis, 8:812-826.

[192] Hattiangady B, Shuai B, Cai J, Coksaygan T, Rao MS, Shetty AK (2007). Increased dentate neurogenesis after grafting of glial restricted progenitors or neural stem cells in the aging hippocampus. Stem Cells, 25:2104-2117.

[193] Park DH, Eve DJ, Sanberg PR, Musso J, 3rd, Bachstetter AD, Wolfson A, et al. (2010). Increased neuronal proliferation in the dentate gyrus of aged rats following neural stem cell implantation. Stem Cells Dev, 19:175-180.

[194] Shetty AK, Hattiangady B (2016). Grafted Subventricular Zone Neural Stem Cells Display Robust Engraftment and Similar Differentiation Properties and Form New Neurogenic Niches in the Young and Aged Hippocampus. Stem Cells Transl Med, 5:1204-1215.

[195] Zhang Y, Kim MS, Jia B, Yan J, Zuniga-Hertz JP, Han C, et al. (2017). Hypothalamic stem cells control ageing speed partly through exosomal miRNAs. Nature, 548:52-57.

[196] Park D, Yang G, Bae DK, Lee SH, Yang YH, Kyung J, et al. (2013). Human adipose tissue-derived mesenchymal stem cells improve cognitive function and physical activity in ageing mice. J Neurosci Res, 91:660-670.

[197] Cao N, Liao T, Liu J, Fan Z, Zeng Q, Zhou J, et al. 
(2017). Clinical-grade human umbilical cord-derived mesenchymal stem cells reverse cognitive aging via improving synaptic plasticity and endogenous neurogenesis. Cell Death Dis, 8:e2996.

[198] Blurton-Jones M, Kitazawa M, Martinez-Coria H, Castello NA, Muller FJ, Loring JF, et al. (2009). Neural stem cells improve cognition via BDNF in a transgenic model of Alzheimer disease. Proc Natl Acad Sci U S A, 106:13594-13599.

[199] Ager RR, Davis JL, Agazaryan A, Benavente F, Poon WW, LaFerla FM, et al. (2015). Human neural stem cells improve cognition and promote synaptic growth in two complementary transgenic models of Alzheimer's disease and neuronal loss. Hippocampus, 25:813-826.

[200] Kim JA, Ha S, Shin KY, Kim S, Lee KJ, Chong YH, et al. (2015). Neural stem cell transplantation at critical period improves learning and memory through restoring synaptic impairment in Alzheimer's disease mouse model. Cell Death Dis, 6:e1789.

[201] Fan J, An X, Yang Y, Xu H, Fan L, Deng L, et al. (2018). MiR-1292 Targets FZD4 to Regulate Senescence and Osteogenic Differentiation of Stem Cells in TE/SJ/Mesenchymal tissue system via the Wnt/ $\beta$-catenin Pathway. Aging Dis. 9:1103-1121.

[202] Sarkar S (2013). Regulation of autophagy by mTORdependent and mTOR-independent pathways: autophagy dysfunction in neurodegenerative diseases and therapeutic application of autophagy enhancers. Biochem Soc Trans, 41 (5), 1103-1130.

[203] Ravikumar B, Vacher C, Berger Z, Davies JE, Luo S, Oroz LG, Scaravilli F, Easton DF, Duden R, O'Kane CJ, Rubinsztein DC (2004). Inhibition of mTOR induces autophagy and reduces toxicity of polyglutamine expansions in fly and mouse models of Huntington disease. Nat Genet, 36 (6), 585-595.

[204] Benjamin D, Colombi M, Moroni C, Hall MN (2011). Rapamycin passes the torch: a new generation of mTOR inhibitors. Nat Rev Drug Discov, 10 (11), 868880.

[205] Lim H, Lim YM, Kim KH, Jeon YE, Park K, Kim J, Hwang HY, Lee DJ, Pagire H, Kwon HJ, Ahn JH, Lee MS (2018). A novel autophagy enhancer as a therapeutic agent against metabolic syndrome and diabetes. Nat Commun, 9 (1), 1438-018-03939-w.

[206] Moulis M, Vindis C (2018). Autophagy in Metabolic Age-Related Human Diseases. Cells, 7 (10), 10.3390/cells7100149.

[207] Dowling RJ, Goodwin PJ, Stambolic V (2011). Understanding the benefit of metformin use in cancer treatment. BMC Med, 9: 33.

[208] Shi WY, Xiao D, Wang L, Dong LH, Yan ZX, Shen ZX, Chen SJ, Chen Y, Zhao WL (2012). Therapeutic metformin/AMPK activation blocked lymphoma cell growth via inhibition of mTOR pathway and induction of autophagy. Cell Death Dis, 3: e275.

[209] Park D, Jeong H, Lee MN, Koh A, Kwon O, Yang YR, Noh J, Suh PG, Park H, Ryu SH (2016). Resveratrol induces autophagy by directly inhibiting mTOR through ATP competition. Sci Rep, 6: 21772.
[210] Hu J, Han H, Cao P, Yu W, Yang C, Gao Y, Yuan W (2017). Resveratrol improves neuron protection and functional recovery through enhancement of autophagy after spinal cord injury in mice. Am $\mathbf{J}$ Transl Res, 9: 4607-4616.

[211] Fu L, Kim YA, Wang X, Wu X, Yue P, Lonial S, Khuri FR, Sun SY (2009). Perifosine inhibits mammalian target of rapamycin signaling through facilitating degradation of major components in the mTOR axis and induces autophagy. Cancer Res, 69 (23): 8967-8976.

[212] Vingtdeux V, Chandakkar P, Zhao H, d'Abramo C, Davies P, Marambaud P (2011). Novel synthetic small-molecule activators of AMPK as enhancers of autophagy and amyloid-beta peptide degradation. FASEB J, 25 (1): 219-231.

[213] Savolainen MH, Richie CT, Harvey BK, Mannisto PT, Maguire-Zeiss KA, Myohanen TT (2014). The beneficial effect of a prolyl oligopeptidase inhibitor, KYP-2047, on alpha-synuclein clearance and autophagy in A30P transgenic mouse. Neurobiol Dis, 68:1-15.

[214] Kuo SY, Castoreno AB, Aldrich LN, Lassen KG, Goel G, Dancik V, Kuballa P, et al (2015). Small-molecule enhancers of autophagy modulate cellular disease phenotypes suggested by human genetics. Proc Natl Acad Sci U S A, 112 (31): E4281-7.

[215] Zhou J, Tan SH, Nicolas V, Bauvy C, Yang ND, Zhang J, Xue Y, Codogno P, Shen HM (2013). Activation of lysosomal function in the course of autophagy via mTORC1 suppression and autophagosome-lysosome fusion. Cell Res, 23:508523.

[216] Feldman ME, Apsel B, Uotila A, Loewith R, Knight ZA, Ruggero D, Shokat KM (2009). Active-site inhibitors of mTOR target rapamycin-resistant outputs of mTORC1 and mTORC2. PLoS Biol, 7 (2): e38.

[217] Liu Q, Chang JW, Wang J, Kang SA, Thoreen CC, Markhard A, Hur W, Zhang J, Sim T, Sabatini DM, Gray NS (2010). Discovery of 1-(4-(4propionylpiperazin-1-yl)-3-(trifluoromethyl)phenyl)9-(quinolin-3-yl)benz o[h][1,6]naphthyridin-2(1H)one as a highly potent, selective mammalian target of rapamycin (mTOR) inhibitor for the treatment of cancer. J Med Chem, 53:7146-7155.

[218] Thoreen CC, Kang SA, Chang JW, Liu Q, Zhang J, Gao Y, Reichling LJ, Sim T, Sabatini DM, Gray NS (2009). An ATP-competitive mammalian target of rapamycin inhibitor reveals rapamycin-resistant functions of mTORC1. J Biol Chem, 284: 8023-8032. Raynaud FI, Eccles S, Clarke PA, Hayes A, Nutley B, Alix S, Henley A, Di-Stefano F, Ahmad Z, Guillard S, Bjerke LM, Kelland L, et al (2007). Pharmacologic characterization of a potent inhibitor of class I phosphatidylinositide 3-kinases. Cancer Res, 67: 5840-5850.

[220] Jaimovich E, Mattei C, Liberona JL, Cardenas C, Estrada M, Barbier J, Debitus C, Laurent D, Molgo J (2005). Xestospongin B, a competitive inhibitor of IP3-mediated $\mathrm{Ca} 2+$ signalling in cultured rat 
myotubes, isolated myonuclei, and neuroblastoma (NG108-15) cells. FEBS Lett, 579:2051-2057.

[221] Criollo A, Maiuri MC, Tasdemir E, Vitale I, Fiebig AA, Andrews D, et al (2007). Regulation of autophagy by the inositol trisphosphate receptor. Cell Death Differ, 14:1029-1039.

[222] Chiong E, Lee IL, Dadbin A, Sabichi AL, Harris L, Urbauer D, McConkey DJ, Dickstein RJ, Cheng T, Grossman HB (2011). Effects of mTOR inhibitor everolimus (RAD001) on bladder cancer cells. Clin Cancer Res, 17:2863-2873.

[223] Crazzolara R, Bradstock KF, Bendall LJ (2009). RAD001 (Everolimus) induces autophagy in acute lymphoblastic leukemia. Autophagy, 5:727-728.

[224] Yang Y, Chen S, Zhang Y, Lin X, Song Y, Xue Z, Qian H, Wang S, Wan G, Zheng X, Zhang L (2017). Induction of autophagy by spermidine is neuroprotective via inhibition of caspase 3-mediated Beclin 1 cleavage. Cell Death Dis, 8:e2738.

[225] Pietrocola F, Lachkar S, Enot DP, Niso-Santano M, Bravo-San Pedro JM, Sica V, Izzo V, Maiuri MC, Madeo F, Marino G, Kroemer G (2015). Spermidine induces autophagy by inhibiting the acetyltransferase EP300. Cell Death Differ, 22:509-516.

[226] Song KS, Kim JS, Yun EJ, Kim YR, Seo KS, Park JH, Jung YJ, Park JI, Kweon GR, Yoon WH, Lim K, Hwang BD (2008). Rottlerin induces autophagy and apoptotic cell death through a PKC-delta-independent pathway in HT1080 human fibrosarcoma cells: the protective role of autophagy in apoptosis. Autophagy, 4:650-658.

[227] Qi P, He Z, Zhang L, Fan Y, Wang Z (2016). Rottlerininduced autophagy leads to apoptosis in bladder cancer cells. Oncol Lett, 12:4577-4583.

[228] Zhang LX, Zhao HJ, Sun DL, Gao SL, Zhang HM, Ding XG (2017). Niclosamide attenuates inflammatory cytokines via the autophagy pathway leading to improved outcomes in renal ischemia/reperfusion injury. Mol Med Rep, 16:18101816.

[229] Balgi AD, Fonseca BD, Donohue E, Tsang TC, Lajoie P, Proud CG, Nabi IR, Roberge M (2009). Screen for chemical modulators of autophagy reveals novel therapeutic inhibitors of mTORC1 signaling. PLoS One, 4: e7124.

[230] Tasdemir E, Maiuri MC, Galluzzi L, Vitale I, Djavaheri-Mergny M, D'Amelio M, Criollo A, Morselli E, Zhu C, Harper F, Nannmark U, Samara C, Pinton P, Vicencio JM, Carnuccio R, Moll UM, Madeo F, Paterlini-Brechot P, Rizzuto R, Szabadkai G, Pierron G, Blomgren K, Tavernarakis N, Codogno P, Cecconi F, Kroemer G (2008). Regulation of autophagy by cytoplasmic p53. Nat Cell Biol, 10: 676687.

[231] Xia Q, Zheng Y, Jiang W, Huang Z, Wang M, Rodriguez R, Jin X (2016). Valproic acid induces autophagy by suppressing the Akt/mTOR pathway in human prostate cancer cells. Oncol Lett, 12:18261832 .
Fu J, Shao CJ, Chen FR, Ng HK, Chen ZP (2010). Autophagy induced by valproic acid is associated with oxidative stress in glioma cell lines. Neuro Oncol, 12: 328-340.

[233] Huang Y, Zhou J, Luo S, Wang Y, He J, Luo P, Chen Z, Liu T, Tan X, Ou J, Miao H, Liang H, Shi C (2018). Identification of a fluorescent small-molecule enhancer for therapeutic autophagy in colorectal cancer by targeting mitochondrial protein translocase TIM44. Gut, 67:307-319.

[234] Yang YF, Wu CC, Chen WP, Chen YL, Su MJ (2011). Prazosin induces p53-mediated autophagic cell death in H9C2 cells. Naunyn Schmiedebergs Arch Pharmacol, 384:209-216.

[235] Kania E, Pajak B, O'Prey J, Sierra Gonzalez P, Litwiniuk A, Urbanska K, Ryan KM, Orzechowski A (2017). Verapamil treatment induces cytoprotective autophagy by modulating cellular metabolism. FEBS J, 284:1370-1387.

[236] Zhang L, Yu J, Pan H, Hu P, Hao Y, Cai W, Zhu H, Yu AD, Xie X, Ma D, Yuan J (2007). Small molecule regulators of autophagy identified by an image-based high-throughput screen. Proc Natl Acad Sci U S A, 104:19023-19028.

[237] Zhu Y, Tchkonia T, Fuhrmann-Stroissnigg H, Dai HM, Ling YY, Stout MB, et al (2016). Identification of a novel senolytic agent, navitoclax, targeting the Bcl-2 family of anti-apoptotic factors. Aging Cell, 15:428-435.

[238] Yousefzadeh MJ, Zhu Y, McGowan SJ, Angelini L, Fuhrmann-Stroissnigg H, Xu M, et al (2018). Fisetin is a senotherapeutic that extends health and lifespan. EBioMedicine, 36:18-28.

[239] Zhu Y, Doornebal EJ, Pirtskhalava T, Giorgadze N, Wentworth M, Fuhrmann-Stroissnigg H, et al (2017). New agents that target senescent cells: the flavone, fisetin, and the BCL-XL inhibitors, A1331852 and A1155463. Aging (Albany NY), 9:955-963.

[240] Zhang XJ, Jia SS (2016). Fisetin inhibits laryngeal carcinoma through regulation of AKT/NFkappaB/mTOR and ERK1/2 signaling pathways. Biomed Pharmacother, 83:1164-1174.

[241] Zhu Y, Tchkonia T, Pirtskhalava T, Gower AC, Ding H, Giorgadze N, Palmer AK, Ikeno Y, et al (2015). The Achilles' heel of senescent cells: from transcriptome to senolytic drugs. Aging Cell, 14:644658.

[242] Triantafyllou A, Mylonis I, Simos G, Bonanou S, Tsakalof A (2008). Flavonoids induce HIF-1alpha but impair its nuclear accumulation and activity. Free Radic Biol Med, 44:657-670.

[243] Makhov P, Golovine K, Teper E, Kutikov A, Mehrazin R, Corcoran A, Tulin A, Uzzo RG, Kolenko VM (2014). Piperlongumine promotes autophagy via inhibition of $\mathrm{Akt} / \mathrm{mTOR}$ signalling and mediates cancer cell death. Br J Cancer, 110:899-907.

[244] Golovine KV, Makhov PB, Teper E, Kutikov A, Canter D, Uzzo RG, Kolenko VM (2013). Piperlongumine induces rapid depletion of the 
androgen receptor in human prostate cancer cells. Prostate, 73:23-30.

[245] Wang Y, Chang J, Liu X, Zhang X, Zhang S, Zhang $X$, Zhou D, Zheng G (2016). Discovery of piperlongumine as a potential novel lead for the development of senolytic agents. Aging (Albany NY), 8:2915-2926.

[246] Samaraweera L, Adomako A, Rodriguez-Gabin A, McDaid HM (2017). A Novel Indication for Panobinostat as a Senolytic Drug in NSCLC and HNSCC. Sci Rep, 7:1900-017-01964-1.

[247] Fuhrmann-Stroissnigg H, Ling YY, Zhao J, McGowan SJ, Zhu Y, Brooks RW, et al (2017). Identification of
HSP90 inhibitors as a novel class of senolytics. Nat Commun, 8:422-017-00314-z.

[248] Li H, Zhu L, Chen H, Li T, Han Q, Wang S, et al (2018). Generation of Functional Hepatocytes from Human Adipose-Derived $\mathrm{MYC}^{+} \mathrm{KLF}^{+} \mathrm{GMNN}^{+}$ Stem Cells Analyzed by Single-Cell RNA-Seq Profiling. Stem Cells Transl Med, 7(11):792-805.

[249] Wang S, Zhu R, Li H, Li J, Han Q, Zhao RC (2018). Mesenchymal stem cells and immune disorders: from basic science to clinical transition. Front Med, Jul 30, in press. 